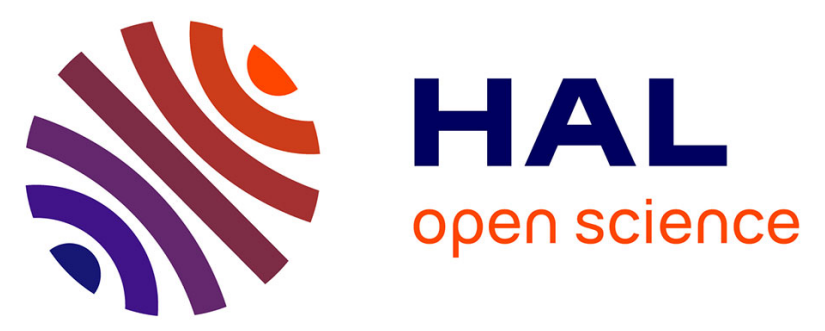

\title{
Preventive remanufacturing planning of production equipment under operational and imperfect maintenance constraints: A hybrid genetic algorithm based approach
}

Yassir Bensmain, Mohammed Dahane, Mohammed Bennekrouf, Zaki Sari

\section{- To cite this version:}

Yassir Bensmain, Mohammed Dahane, Mohammed Bennekrouf, Zaki Sari. Preventive remanufacturing planning of production equipment under operational and imperfect maintenance constraints: A hybrid genetic algorithm based approach. Reliability Engineering and System Safety, 2019, 185, pp.546-566. 10.1016/j.ress.2018.09.001 . hal-03233482

\section{HAL Id: hal-03233482 \\ https://hal.science/hal-03233482}

Submitted on 21 Oct 2021

HAL is a multi-disciplinary open access archive for the deposit and dissemination of scientific research documents, whether they are published or not. The documents may come from teaching and research institutions in France or abroad, or from public or private research centers.
L'archive ouverte pluridisciplinaire HAL, est destinée au dépôt et à la diffusion de documents scientifiques de niveau recherche, publiés ou non, émanant des établissements d'enseignement et de recherche français ou étrangers, des laboratoires publics ou privés.

\section{(ㄷ)(1) $\$$}

Distributed under a Creative Commons Attribution - NonCommerciall 4.0 International 


\title{
Optimal preventive remanufacturing planning of production equipment under operational and imperfect maintenance constraints: A hybrid genetic algorithm based approach
}

\author{
Yassir Bensmain ${ }^{\mathrm{a}, 1}$, Mohammed Dahane ${ }^{\mathrm{b}, *}$, Mohammed Bennekrouf ${ }^{\mathrm{c}, 2}$, Zaki Sari $^{\mathrm{a}, 3}$ \\ ${ }^{a}$ Manufacturing Engineering Laboratory of Tlemcen, Abou Bekr Belkaid University, BP 119, Chetouane, Tlemcen, Algeria \\ ${ }^{b}$ Université de Lorraine, LGIPM, F-57000 Metz, France \\ ${ }^{c}$ High School of Applied Science of Tlemcen, BP 165 RP Bel horizon, Tlemcen, Algeria
}

\begin{abstract}
Remanufacturing an equipment before the end of its life may generate substantial profits for both the user and the remanufacturer. However, the equipment operating conditions as well as the quality of maintenance actions undergone throughout the life of equipment largely affect the total life cycle costs (LCCs) from the user's perspective, and the quality of the recovered equipment from the remanufacturer's perspective. This research aims at investigating the remanufacturing opportunities of production equipment used to produce a single product in order to meet deterministic and dynamic demands over a finite horizon. Preventive maintenance actions on equipment are assumed to be imperfect. Indeed, when performed, these actions can improve the equipment to reach a state between the "As-bad-as-new" level and the "As-good-as-old" level. It is assumed that the stakeholders (the equipment's user and the Original Equipment Manufacturer) are interested by all remanufacturing opportunities. The objective of the present work is to develop an integrated approach to jointly optimize the production plan, the remanufacturing plan and the quality of spare parts used in each remanufacturing action.

In order to minimize the total cost during the production horizon, a mixed-integer nonlinear program (MINLP) is developed. The optimization problem is solved using a hybrid genetic algorithm based on a fix-and-relax heuristic. A numerical experiment and a sensitivity analysis are presented to illustrate the applicability of the proposed approach.

Keywords: Active remanufacturing, Imperfect maintenance, Production planning, Genetic algorithm, Fix and Relax heuristic
\end{abstract}

\section{Introduction}

With the growing level of environmental awareness and the emerging circular economy over the last decade, many companies have started shifting towards a business model that is more consistent with the objectives of sustainable development. These objectives are considered as challenges that seek to improve profitability, 5 reduce pollution and preserve resources. According to Lambin (2009), around $20 \%$ of the world population living in industrialized countries consumes $80 \%$ of the world's resources. The traditional business model follows a "cradle to grave" process that is based on a linear product life cycle, i.e. raw material extraction, manufactur-

\footnotetext{
* Corresponding author. Tel.: +33.372748684

Email address: mohammed.dahane@univ-lorraine.fr (Mohammed Dahane)

$1_{\text {yassir.bensmain@gmail.com }}$

2 mbenkrouf@yahoo.fr

${ }^{3}$ z_sari@mail.univ-tlemcen.dz
} 
ing, distribution, consumption and accumulation of waste. Recently, a new economic model, called the "Loop economic model" has replaced this traditional business model. The new model is based on a "Cradle to a new cradle" process that is based on various remanufacturing strategies.

As reported by Sinha et al. (2016), the concept of "Remanufacturing" was suggested for the first time in a scientific context by Lund and Mundial (1984). These two authors described the concept as "An industrial process in which worn-out products are restored to like-new condition. Through a series of industrial processes in a factory environment, a discarded product is completely disassembled; usable parts are cleaned, refurbished, and put into inventory. Then the product is reassembled from the old parts (and where necessary, new parts) to produce a unit fully equivalent in performance to the original new product". This process has recently become widely prevalent in the industrial countries in general, and in the United States in particular. As reported by the United States International Trade Commission (USITC), the United States (U.S.A) is the largest producer, consumer, and exporter of remanufactured goods in the world. Solely between 2009 and 2011, the value of remanufactured production in the U.S.A. grew by $15 \%$ to at least 43 billion dollars, and supported 180000 full-time jobs spread out over 2900 firms, with 20 employees or more. Moreover, this same commission notes that the sectors involving the greatest number of remanufacturing firms include the machinery industry (742 firms), followed by information technology (IT) products (297 firms) and motor vehicle parts (283 firms), in addition to other sectors like aerospace, consumer products, Heavy-Duty \& Off-Road (HDOR) equipment and medical devices. In the European Union (EU), the remanufactured production represents a value of 40 billion Euros, and supports 300000 jobs (USITC et al. 2012).

In addition to its importance with regard to the number of firms, the machinery sector is estimated to be the fourth largest remanufacturing sector in terms of production value (after aerospace, HDOR equipment, and motor vehicle parts). Moreover, this sector extends over a broad diversification across a variety of industries and covers a diverse range of products, like the industrial valves, turbines, machine tools, textile machinery, and compressors (USITC et al. 2012). Unfortunately, although the growing voices requesting original equipment manufacturers (OEMs) to assume responsibility for the take-back of their used machines or components, a large number of them, especially small and medium enterprises (SMEs) cannot afford to implement global end-of-life (EOL) strategies. Their arguments are the extra costs and the unpredictable demands resulting in inefficient reverse product flows (Karaulova and Bashkite, 2016).

Indeed, implementing an efficient EOL strategy turns out to be a very complicated task for OEMs who generally confront a great and serious uncertainty problem about returned used products. Practitioners assume that the main uncertainty that causes major problems is the lack of a true collaboration between these manufacturers and their customers. More precisely, many OEMs sever their ties and have no relation with their customers immediately after the end of the warranty period, which causes greater uncertainty about the return time, quantity, quality, value and location of the EOL products. In addition, OEMs generally face increasing competition from third-party remanufacturers (3PRs) exploiting the lack of communication between the OEMs and their customers in order to maximize their profits without considering global and sustainable interests. Existing literature has primarily argued that the presence of 3PRs is detrimental for OEMs who should undertake preemptive remanufacturing in order to prevent or reduce such competition (Agrawal et al., 2015b).

Remanufacturing may be performed on used equipment once it reaches the end of its lifetime. This is the general approach, known to researchers and practitioners, through which owners can achieve the highest profit 
from their equipment. However, when the equipment is used until complete deterioration (the end of its life), its maintenance operation becomes expensive. Furthermore, all possible ways of recovery consume large quantities of energy and resources and produce much more pollution as well. In this context, Liu et al. (2013) introduced the concept of "Active remanufacturing", also known as "Preventive remanufacturing". In this concept, it is required that the product be remanufactured once it reaches the prescribed optimal lifetime, even though it is still functional. On the one hand, the life cycle costs (LCCs), remanufacturing costs and environmental burdens would be substantially reduced; on the other, the above mentioned concept allows extending effectively the product life cycle (PLC), and partially solving the uncertainty problem which is related to time, quality, quantity and value of the returned products (Liu et al., 2016).

Furthermore, identifying the right time to shut down the equipment in order to perform remanufacturing helps realize maximum economic benefits. One approach that can be employed to analyze the economic benefit of products and to make a decision about the optimal timing to remanufacture a used product is the "Life cycle costing (LCC)" methodology, which is defined by the International Standardization Organization (ISO) as the methodology that allows assessing the life cycle costs of used products (Schau et al., 2011). Regarding the machinery sector, the life cycle costs (LCCs) includes the equipment cost, spare parts cost, maintenance cost and depreciation cost. A survey, which was carried out in the United Kingdom, showed that $78 \%$ of industrial respondents rarely use the LCC method (Higham et al., 2015). To the best of our knowledge, only a few published works have, so far, adopted the LCC methodology in the machinery sector and production systems. Bengtsson and Kurdve (2016) presented a case study in which they utilized this methodology in order to make an appropriate decision on whether to acquire a new machine, recondition an existing one, or run it with increased costs and risks.

It should be noted that the life cycle costs (LCCs) of an equipment crucially depend on the depreciation of its value on the one hand, and on values related to reliability parameters, such as equipment failure rates, spare part costs and repair times, on the other (Márquez et al., 2009). The concept of depreciation, which is a major issue in economics, plays an essential role in determining the value of an asset after using it over a long period of time (Olagunju and Yaru, 2014). Similarly, reliability decreases with time; it greatly depends on the frequency of usage of the machine, which is a case that has rarely been investigated in academic literature (Ho et al., 2015). Many researchers assume in their works that the operating conditions are constant. However, in the industrial field, it is found that in several cases, manufacturers use their machines under very different operating conditions, i.e. machines can work continuously or intermittently, with full or partial load (e.g. production rate), etc. In this context, (Martorell et al., 1999) classified the operating conditions as bad, normal or good.

The operating conditions, deterioration pattern and remanufacturing activities are all becoming increasingly interdependent. The present study is therefore motivated by the need to develop an integrated approach that reflects this interdependence in order to create favorable conditions for win-win situations, for both the remanufacturer and the customer.

The remainder of this paper is structured as follows. First, a literature review of related works is provided.

${ }_{85}$ Next, the problem of the study is described and the proposed approach is discussed in sections 3 and 4 . Then, the solution approach is presented in section 5. Section 6 is devoted to the numerical experiment. Section 7 focuses on sensitivity analysis. In the end, some concluding remarks and possible extensions are provided in section 8 . 


\section{Literature review}

For a comprehensive review on the topic, the reader may refer to Atasu et al. (2008), Abbey and Guide Jr (2017), Govindan et al. (2015), Agrawal et al. (2015a), Vahabzadeh and Yusuff (2015), Jayant et al. (2012), Stindt and Sahamie (2014). Moreover, several literature reviews have dealt separately with one specific issue of remanufacturing decision-making, such as product acquisition management (Wei et al., 2015; Priyono et al., and maintenance (Diallo et al., 2016), etc.

The problem under consideration is related to several research fields, which are exposed in the present literature review, i.e. remanufacturing of production equipment (2.1), active remanufacturing (2.2), spare part selection (2.3), and the relationship between production planning and equipment deterioration (2.4).

\subsection{Remanufacturing of production equipments}

According to Chari et al. (2014), remanufacturing is a value recovery option that is available at the end of a product's lifetime in order to extend its original lifespan. Also, it is the process of restoring used products to likenew condition by disassembling, cleaning, repairing or replacing parts, and reassembling them. Remanufacturing of production equipment is becoming increasingly more attractive for OEMs seeking to achieve profitability by reducing energy consumption, limiting raw material usage and labor costs, and enhancing environmental sustainability by reducing landfill waste (Ijomah et al., 2007). Practitioners and researchers have contributed in different ways to this field. Indeed, Steingrímsson et al. (2011) proposed an approach to develop business strategies for competition and collaboration in the remanufacturing market of production equipment, while considering different market players having different characteristics. Cunha et al. (2011) established a technology road mapping technique to show the interrelations between market, equipment and technology parameters. Other studies focused on a specified type of production equipment. For instance, Schraven et al. (2012) proposed a make-to-order (MTO) production strategy for equipment used by automotive OEMs including a modular concept which permits to consider recovered equipment components in engineering and design. da Silva et al. (2012) presented a prototypical implementation of a remanufacturing oriented grinding machine. Based on a storyboard, it is well possible to describe the main activities that are carried out during the machine life cycle, including a comparative life cycle assessment (LCA) with EOL scenarios.

Production equipment can be classified into two main categories, namely (i) the automotive equipment, which includes construction equipment, crawlers, tractors and others; and (ii) the machinery equipment that includes all forms of machines used in manufacturing systems.

A large number of researchers, such as Saavedra et al. (2013), Zhang et al. (2011), Parker (1997) and others, agree on the fact that remanufacturing has become a potential growth partner in the automotive sector, which undoubtedly has been the main driving force of the industry so far. For this particular sector, several contributions were found in the literature. Yi et al. (2016) developed a mixed-integer linear model devoted to determine an optimal design of a closed-loop supply chain (CLSC) network for the construction machinery remanufacturing in order to monitor or control the flows of used products. Sharma et al. (2015) investigated the remanufacturing process and found out that remanufacturing is the primary means by which the customer's requirements and needs are satisfied; it also provides effective product support services for heavy equipment. 
Likewise, Yan (2013) presented an in-depth analysis of the economical, environmental and resource benefits of remanufactured hydraulic valves. The author indicated that remanufacturing can restore the function of invalid hydraulic valves and can save up to $55 \%$ on costs, $85 \%$ on resources and $90 \%$ on materials. Zhou et al. (2012) proposed a quality evaluation model to appraise the reusability degree of the recycling parts of wheel loaders.

In the machinery industry, a large number of studies have addressed various problems encountered in remanufacturing mainly from the OEM's perspectives (Darghouth et al., 2017; Du and Li, 2014; Ferguson et al., 2009). Many of these studies were devoted to machine tools (Ullah et al., 2016; Liu et al., 2014a; Darabă, 2014; Yaoling, 2012; Du et al., 2012); some authors exposed remanufacturing only for a special kind of production machines (Geng et al., 2016; Yang, 2014; Yan, 2013; Hayashi et al., 2013; Yiqing et al., 2006). It is worth noting that the potential benefits of remanufacturing certainly depend on customer requirements. To the best of our knowledge, only a few studies have focused on the remanufacturing of machines, from the user's point of view.

\subsection{Active remanufacturing}

Active remanufacturing engineering, which is based on the theory of the whole life cycle, involves a series of industrial processes of repairing or modifying worn products in an appropriate period of time (Gao et al., 2016). Within this framework, Liu et al. (2016) suggested a model that helps to determine the optimal timing for product remanufacturing from the environmental perspective. The authors applied their model to an engine crankshaft when the environmental impact is defined on the basis of the replacement theory. In another work, Liu et al. (2014b) used the LCA method to determine the optimal timing for the remanufacturing of an engine. The environmental assessment process used in their study takes into account the four product life cycle stages, namely original manufacturing, first-time usage, remanufacturing, and second-time usage. Qingdi and Dan (2013) proposed a time interval decision-making method for active remanufacturing of electro-mechanical products based on game theory and neural network.

Beside the environmental aspect considered in previous works, Gao et al. (2016) considered also the economic aspect in their model in order to determine the optimal active remanufacturing timing for electromechanical products. The environmental impact was converted and integrated in the economic costs using the "Society's Willingness to Pay (WTP)" method. Based on an optimal remanufacturing timing model, a recycling operation mode is given. This mode includes three layers, namely the manufacturing and remanufacturing layer, which in turn includes three parts; then the middle layer which consists of distributors and maintainers; and finally the end-user layer that comprises entities and individuals. In order to test its efficiency, the proposed mode is applied to different types of connecting rods.

Shi and Min (2014) investigated the effect of uncertainties in operations and maintenance (O\&M) costs on remanufacturing and replacement decisions. The authors considered a firm that leases a product composed of durable and nondurable components to a service provider. The remanufacturing options consist of replacing the nondurable parts with new ones, while the replacement options indicate that the product is to be replaced as a whole. Their objective was to determine the optimal timing to perform remanufacturing or replacement when the O\&M costs follow the Geometric Brownian Motion (GBM). By applying the proposed model on photocopiers, they showed that when the O\&M costs become more volatile, it is better to defer remanufacturing and replacement.

Another model for the determination of the active remanufacturing timing was elaborated by Liu et al. 
(2013); it is based on the aspects of the product performance degradation and failure state of key components. The author refers to products with multiple components. Some of them are high value components that contain defective parts that would mostly be replaced during the remanufacturing process.

\subsection{Spare parts selection}

Two thirds of all remanufacturing activities are about the spare part industry (Charter and Gray, 2007). When remanufacturing facilities are available, product recovery can be used as an additional option for spare parts procurement, in order to meet either maintenance (during life cycle) or remanufacturing demands (at the EOL cycle) of other products. In this context, Chari et al. (2013) studied the issue related to the onedimensional warranty. During the warranty period, the manufacturer is committed to repairing all failures by using new or reconditioned spare parts. In order to maximize the expected profits, these authors proposed a mathematical model to calculate the optimal production and warranty parameters. As extension of this work, Chari et al. (2016) treated the same warranty problem by adding other decision variables, such as the sales price, the age and the proportion of reconditioned components.

Despite the economic and environmental benefits of using remanufactured spare parts, the question that still arises is about its ability to meet the user's requirements. Bhakthavatchalam et al. (2015) argued that the reliability of a remanufactured product is an important factor in the remanufacturing decisions. Once refurbished, the part is used for a second time and is supposed to provide a high performance level to the consumer. In fact, remanufactured spare parts have a different operating mode from the new ones; for example, their breakdowns are more frequent. Therefore, their misuse may have adverse effects on the operation and maintenance processes (Dahane et al., 2015). From the user's perspectives, when he decides to remanufacture or replace his equipment, it is important for him to know the cost-effective composition, of new and remanufactured spare parts, that is consistent with the next usage pattern (next operating mode). As far as we know, current literature about machinery and equipment contains only a few research works dealing with the issue of spare part selection for remanufacturing or maintenance operations based on the user's perspectives. Boudhar et al. (2014) investigated the eventual opportunities to use new or remanufactured spare parts in repairing a production machine that was subject to a stochastic degradation. They proposed a heuristic for the determination of the inspection dates as well as the quality of the spare part to use in the next replacement, depending on the degradation level of the operating part. Diallo and Aït-Kadi (2011) examined the reliability properties of systems encountered in industrial settings when new and reconditioned components of the same life distribution but different ages are mixed to perform remanufacturing or maintenance operations. Moreover, Dahane et al. (2015) developed a multi-agent approach for other kinds of systems in order to improve the impact of the spare parts management strategy on an Offshore Wind Turbine (OWT) system during (for maintenance operations) or at the end of its life cycle (for remanufacturing process).

\subsection{Production planning and maintenance}

The main objective of production systems is to satisfy the product demand and prevent any shortage in order to keep the customer loyalty and maximize profitability. However, profitability is directly dependent on the production plan. Over production leads to an increase in inventory-related costs, while less production leads to customer dissatisfaction. Therefore, managers must be capable of providing the adequate economic production quantity for each period of the production horizon in order to avoid these two extreme situations. 
These issues have largely been studied in the literature under different names, namely: "Lot sizing", "Economic manufacturing quantity (EMQ)", "Economic production quantity (EPQ)" or "Economic order quantity (EOQ)". For a comprehensive literature review on this research field, the reader may refer to Bushuev et al. (2015); Wang et al. (2014); Glock et al. (2014); Buschkühl et al. (2010); Ullah and Parveen (2010). However, in most cases, the customer demands may vary from one period to another, which implies a variation in the production rate over the production planning horizon. In this case, one can say that the production machines operate under variable operating conditions.

Furthermore, reliability and maintenance costs of machines are to be regarded as the primary lifecycle cost drivers which the user seeks to minimize beside the inventory-related costs. In addition, machine deteriorations are directly dependent on both time and operating conditions (cycle duration or production rate). Most researchers in the maintenance area assume that the operating conditions are either constant or have no effect on the deterioration process (Hu and Jiang, 2016). Cox (1972) proposed the first condition-dependent failure model for the analysis of survival data in biomedicine. Thereafter, this model was employed to investigate the reliability and maintainability of industrial systems in order to represent the effect of both operational and environmental conditions on system deterioration (Dao and Zuo, 2016; Zhao et al., 2010; Martorell et al., 1999; Kumar and Westberg, 1997). Dao and Zuo (2016) investigated the selective maintenance problem for multi-state components operating under variable loading conditions. The authors proposed a load-dependent degradation model based on the Proportional Hazard Model (PHM) in order to identify the best maintenance strategy that allows maximizing the system reliability in the next missions, within the limits of available resources. Lanza et al. (2009) presented a comprehensive approach to quantify the effect of time-varying loads on machine reliability in order to calculate the optimal time to provide the needed spare parts and perform preventive maintenance $(\mathrm{PM})$ actions.

In regard to the papers dealing with the problem of jointly optimizing production, maintenance and inventory costs, only a few of them have considered the interdependence between the production rate and failure rate. Regarding cutting machines, Cheng et al. (2016) proposed a joint strategy of production control and PM scheduling in which they integrated the load-dependent model previously proposed by Lanza et al. (2009). Regarding the lifetime of cutting tools, these authors aimed to jointly determine the production rate and the number of replacement times of cutting tools in order to minimize the total expected cost per unit item produced. With regard to a multi-product manufacturing system, Dahane et al. (2012) developed a genetic algorithm to determine the optimal production rate that helps to minimize the total cost (inventory, production and reparation) over a finite horizon. Martinelli (2005) considered a single machine, which is characterized by a Markov failure/repair process, with two different failure rates for low and high production proportions.

Several models reported in the maintenance-related literature, including the aforementioned models, assume that a system can be restored as good as new after each PM action. In practice, this assumption is often not true as a unit after PM might usually be younger, but might occasionally be worse than before PM because of faulty procedures (Nakagawa, 1980). This kind of preventive maintenance (PM) is called "Imperfect preventive maintenance (IPM)". Indeed, when IPM is performed, it improves the machine which passes into a state between

"As-good-as-new" and "As-bad-as-old". Many approaches have been proposed for modeling the effects of IPM. The most popular are the age reduction model (Malik, 1979) and the failure rate increase model (Nakagawa, 1988). Based on these two approaches, Lin et al. (2000) proposed a hybrid imperfect maintenance (HIM) model, by introducing both the hazard rate increase factor (HRIF) and the age reduction factor (ARF) in the hazard 
rate function.

However, few works have studied the joint effect of imperfect maintenance policy and variable operating conditions on the performance of production systems. Inspired by the PHM and the HIM models, You et al. (2011) combined these two models in a unified framework to consider the effects of imperfect maintenance actions and operating conditions on the system failure occurrence probability. The resulting model is called the "Extended Proportional Hazard Model (EPHM)". Lu et al. (2012) considered the imperfect maintenance for systems running in a time-varying environment; it was modeled by using the two-state homogeneous Markov process, where one state represents a typical condition, and the other represents a severe condition. The effect of these two conditions is represented by the PHM model and the effect of imperfect maintenance is presented as an HIM model. The authors proved the discontinuity of the hazard rate function of the system in a time-varying environment through a Markov additive process.

\subsection{Contribution}

The remanufacturing of production systems depends both on the operating conditions and maintenance effectiveness. In this context, the main contribution of this paper consists in developing an integrated approach based on the "life cycle costing" method in order to jointly determine the best production plan (operating mode) and the best active remanufacturing plan, when the preventive maintenance actions are imperfect. This integrated optimization aims to minimize the equipment life cycle costs (LCCs), which include maintenance costs, depreciation expense and remanufacturing costs, as well as the inventory costs of the manufactured products. The considered equipment (machine) is used to satisfy deterministic and dynamic demands during a finite horizon, which may consist of several periods. Therefore, the production planning consists of determining the optimal (or near-optimal) production rate for each period, while the remanufacturing planning aims to identify simultaneously the best timing to remanufacture the equipment and the most appropriate spare part (new or remanufactured) for each operating mode. This study allows highlighting the effects of production constraints on the reliability and depreciation value of the equipment, and consequently on the remanufacturing decisions during a finite horizon.

\section{System description and assumptions}

The production equipment considered here is composed of one main part (core) and a set of secondary parts. The key part is non-durable, while the secondary parts are durable. The equipment is used to produce one single product. The equipment's user must satisfy a deterministic and dynamic demand during a finite production horizon that consists of several periods of equal durations. The demand for each period must be delivered, without any delay, at the end of that period (the delivery time). During the planning horizon, the equipment operates under variable production rates, which are expressed in number of units produced per unit of time.

In terms of reliability, the equipment is subject to a stochastic degradation that depends on the degradation of its core (main part) only. Consequently, the maintenance operations concern only that part. The core degradation can be measured by its failure rate, which increases with the operating time and the operating conditions (production rate). To address the deterioration issue, regular IPM actions are achieved following a predetermined plan in order to reduce the equipment failures. Moreover, when a random failure occurs between 
two successive PM actions, a corrective maintenance (CM) action is carried out in order to restore the equipment to an as-bad-as-old (ABAO) condition.

Following an after-sales service strategy, the OEM is responsible for remanufacturing the equipment in use

are classified into $N q$ qualities according to the effectiveness of the remanufacturing process performed by the OEM.

- have an initial state similar to that of new parts, i.e. when installing a remanufactured spare part, it brings the equipment back to an "As good as new (AGAN)" state.

- Their cost is smaller than to that of a new part $\left(A C_{N q-1}<\ldots<A C_{1}<A C_{0}\right)$.

- When using a remanufactured part of type $q \geq 1$, the equipment degrades rapidly as compared to equipment consisting of part of type $q-1$.

In terms of ownership, the equipment value decreases gradually with its increasing length of operation. As for the equipment reliability, the depreciation expense depends only on that of the main part. It can be estimated based on the production rate (the number of units produced per unit of time) and the operating conditions. However, the equipment can be restored to its initial value after each remanufacturing operation. The system under study is illustrated in Fig. 1.

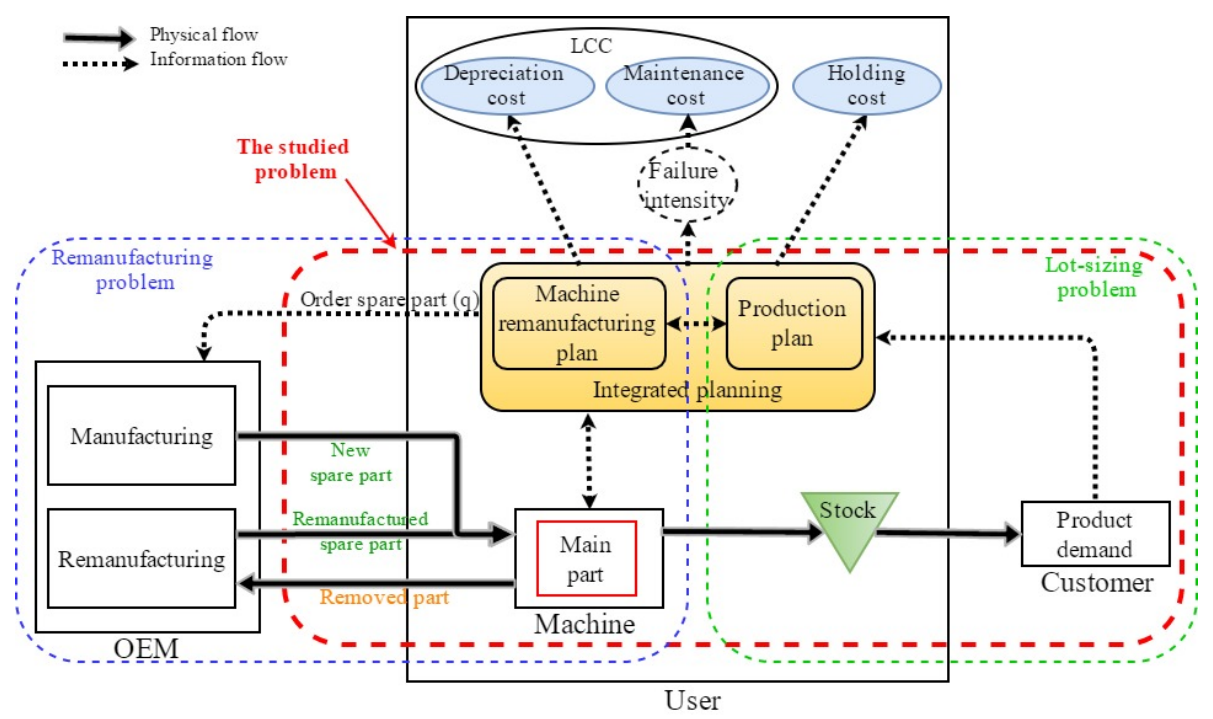

Fig. 1. System description

We define the variables and the parameters of the model as follows:

\section{Index}

$n \quad$ Index of production periods.

$t \quad$ Index of the operating time.

Index of spare parts qualities. 


\section{Parameters}

$N \quad$ Number of production periods in the planning horizon.

$N q \quad$ Number of spare parts qualities.

$D_{n} \quad$ Demand to the period $n$ (i.e. which must be delivered at the end of period $n$ ).

$T_{n} \quad$ Time at the end of period $n$.

$U^{\max } \quad$ Maximum production rate per unit of time.

$\lambda_{0,0}(t) \quad$ Baseline failure rate function of an equipment that operates only with new main parts under the maximum production rate.

$\lambda_{n}(t) \quad$ Equipment failure rate function in period $n$.

$C^{\text {rem }} \quad$ Fixed cost of remanufacturing the equipment.

$C C M \quad$ Cost of one CM action.

$D M \quad$ Duration of one IPM action.

$D R \quad$ Duration of a remanufacturing action.

$h \quad$ Holding cost of one manufactured product per period.

$A C_{q} \quad$ Factory cost of spare parts of quality $q$.

$K_{n} \quad$ Adjustment factor between 0 and 1 which is used to establish the effect of production intensity over period $n$ on equipment's depreciation.

$v 1, v 2 \quad$ Minimum values of high and intensive production rates respectively.

$T P U_{q} \quad$ Maximum number of units that can be produced by the equipment with a part of quality $q$ under the production rate $U^{\max }$.

$S V_{q} \quad$ Residual value of a part of quality $q$ at the end of its life (after producing $T P U_{q}$ units under the production rate $U^{\max }$.

Outputs

$O T_{n} \quad$ Expected operating time in period $n$.

$D T_{n} \quad$ Expected downtime in period $n$.

$C P M_{n} \quad$ Cost incurred when performing a PM action at the beginning of period $n$.

$F N_{n} \quad$ Expected failure number over period $n$.

$V_{n} \quad$ Expected equipment's value at the end of period $n$.

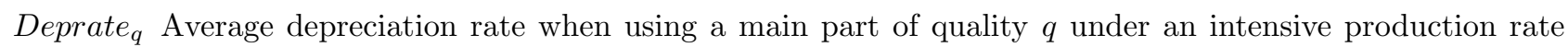
$\left(U_{n} \in\left[b, U^{\max }\right]\right)$.

$S_{n} \quad$ Quantity of manufactured products remaining in the stock at the end of period $n$. 
$\operatorname{Depr}_{n} \quad$ Total expected depreciation expense in period $n$.

$C_{n} \quad$ Total expected maintenance cost in period $n$.

\section{Problem formulation}

$$
\begin{aligned}
\text { Minimize } T C= & \sum_{n=1}^{N} C_{n}+\sum_{n=1}^{N} h \cdot S_{n}+\sum_{q=0}^{N q-1} X_{q, 1} A C_{q} \\
& +\sum_{n=2}^{N}\left[\sum_{q=0}^{N q-1}\left(X_{q, n}\left(A C_{q}-V_{n-1}\right)\right)+C^{r e m} \sum_{q=0}^{N q-1} X_{q, n}\right]-V_{N}
\end{aligned}
$$

Subject to:

$$
\begin{gathered}
\sum_{q=0}^{N q-1} X_{q, n} \leq 1, \quad \forall n \in[1, N] \\
S_{n}=S_{n-1}+U_{n} O T_{n}-D_{n}, \quad \forall n \in[1, N]
\end{gathered}
$$




$$
\begin{gathered}
U_{n} \leq U^{\max }, \quad \forall n \in[1, N] \\
Y_{n} \geq 0, \quad \forall n \in[1, N] \\
Y_{q, n}=\left\{\begin{array}{c}
Y_{q, n-1} \text { if } \sum_{q^{\prime}=0}^{N q-1} X_{q^{\prime}, n}=0 \quad \forall n \in[1, N], q \in[0, N q-1] \\
X_{q, n} \quad \text { otherwise } \\
X_{q, n} \in\{0,1\}, \quad \forall n \in[1, N], q \in[0, N q-1]
\end{array}\right.
\end{gathered}
$$

The objective function (1) expresses the total expected cost during the planning horizon. The two first terms represent the total maintenance cost and total inventory cost, respectively. The third term is the acquisition cost of the spare part used at the beginning of the horizon. The fourth term represents the total remanufacturing cost: (i) if a remanufacturing action is performed at the beginning of period $n$, a variable cost is included; this variable represents the difference between the acquisition cost $A C_{q}$ of the ordered spare part and the salvage value of the removed part; (ii) in addition, a fixed cost $C^{r e m}$ is also required; this includes the costs of transportation of the ordered part, disassembly/assembly, cleaning, and testing. Finally, the fifth term designates the residual value of the part returned to the OEM at the end of the horizon.

Constraint (2) guarantees the unicity of the spare part type that is selected to replace the removed part when performing a remanufacturing action. Constraint (3) represents the inventory balancing, which ensures that the remaining products from previous periods and those produced during the period $n$ are used to meet the demands of that period $n$ or to satisfy the requirements of the following periods. Constraint (4) makes sure that the production rate during each period $n$ does not exceed the maximal production rate. Constraint (5) prevents the equipment value to go down below zero. Constraint (6) links $Y_{q, n}$ with $X_{q, n}$ in order to assure that the type of part in use cannot be changed until the next remanufacturing action. Finally, constraint (7) defines the nature of variables $X_{q, n}$.

The next section attempts to evaluate the costs and to establish the relationships existing between production, maintenance and depreciation.

\subsection{Evaluation of maintenance costs while taking into account remanufacturing}

The maintenance strategy under consideration is the well-known PM policy with minimal repair at failure (Jardine and Tsang, 2013). PM actions are assumed to be performed only at the beginning of production periods. They are considered as imperfect, i.e. when performed, they are supposed to improve the equipment core (the main part) to reach a state between AGAN and ABAO. Whenever a random failure occurs between two PM actions, the equipment undergoes minimal repair (corrective maintenance $(\mathrm{CM})$ ) to restore it to a state it was in before failure, without improving the failure rate. Therefore, the expected maintenance cost in period $n$ can be expressed as follows:

$$
C_{n}=C P M_{n}+C C M \cdot F N_{n}, \quad \forall n \in[1, N]
$$


The first part represents the cost engendered if a PM action is performed at the beginning of period $n$.

It is worth recalling that either the PM action or the remanufacturing operation must be performed at the beginning of each period. The second part represents the total expected costs of CM actions to be conducted during the period $n$. These costs are expressed as a function of the average number of failures $F N_{n}$, which can be estimated in terms of the failure rate function $\lambda_{n}(t)$ over the period $n$.

$$
F N_{n}=\int_{0}^{O T_{n}} \lambda_{n}(t) . d t, \quad \forall n \in[1, N]
$$

Here, $O T_{n}$ denotes the expected operating time in period $n$. Knowing that the PM actions or the remanufacturing operations can stop equipment operation for some units of time $D T_{n}$, which can be equal to $D M$ for the PM or $D R$ for remanufacturing (Eq. 10).

$$
\begin{gathered}
O T_{n}=T_{n}-T_{n-1}-D T_{n}, \quad \forall n \in[1, N] \\
D T_{n}=\left\{\begin{array}{cc}
D R & \text { if } \sum_{q^{\prime}=0}^{N q-1} X_{q^{\prime}, n}=1 \\
D M & \text { otherwise }
\end{array} \quad \forall n \in[1, N]\right.
\end{gathered}
$$

The failure rate function $\lambda_{n}(t)$ is used to estimate the average number of failures, which can be different for each period. This number depends on the variable operating conditions (production rates), on the imperfect maintenance and on the quality of remanufacturing as well. As previously done by (You et al., 2011) and (Lu et al., 2012), the PHM and the HIM models are combined to estimate the failure rate function for each period.

The PHM model is one of the most powerful and most popular statistical models that may be used for modeling degrading systems under variable working conditions (Jafari and Makis, 2015). According to this model, the failure rate of a system is a multiplicative function of a baseline function $h_{0}(t)$, which represents the failure rate under the nominal conditions, and a second function $\Psi(z)$, called "Risk function". This function incorporates the effects of the variable working conditions. The general form of a PHM model can be defined as follows:

$$
h(t)=\Psi(z(t)) \cdot h_{0}(t), \quad t \geq 0
$$

where $z(t)$ is a vector that represents the variable working conditions at a given instant $t$.

On the other hand, the HIM model is based on the following idea: if the failure rate function is $h_{i-1}(t)$ before the $i^{t h}$ IPM (imperfect PM) action, it becomes $a_{i} h_{i-1}\left(b_{i} y_{i}+t^{\prime}\right)$ after this action, where $y_{i}$ is the effective age of the equipment just before the $i^{t h}$ IPM action, $t^{\prime}$ is the elapsed time since the $i^{t h}$ IPM and before the $(i+1)^{t h}$ IPM action, while $a_{i}$ and $b_{i}$ represent the hazard rate increase factor (HRIF) and the age reduction factor $(\mathrm{ARF})$, respectively. These two parameters reflect the effect of the imperfect maintenance actions on equipment degradation $\left(a_{i} \geq 1\right.$, and $\left.b_{i} \in[0,1]\right)$.

Therefore, in the case of equipment designed to operate under variable conditions and IPM, the failure rate function after the $(i-1)^{\text {th }}$ IPM action can be expressed as follows:

$$
h_{i}(t)=\left\{\begin{array}{ll}
h_{0}(t) \cdot \Psi(z(t)), & \text { if } i=1 \\
A_{i-1} h_{0}\left(b_{i-1} y_{i-1}+t\right) \cdot \Psi\left(z\left(\text { tot }_{i-1}+t\right)\right) & \text { otherwise }
\end{array} \quad t \in\left[0, \text { tot }_{i}-\text { tot }_{i-1}\right]\right.
$$


where tot $_{i}$ is the total operating time of the equipment before the $(i-1)^{\text {th }} \mathrm{PM}$ action.

The term "working conditions" in our model, designates the operating conditions. It represents the production rates, which are expressed as the number of units produced per unit of time. To adapt the hybrid PHM-IHM model to the system under study, it is required to develop its main elements as follows:

1. In the model suggested in the present study, it is assumed that the nominal conditions are relevant to the maximal production rate (Dahane et al. 2012). Thus, the baseline failure rate function $\lambda_{0}(t)$ is equivalent to that of a system operating with the maximum production rate $U^{\text {max }}$.

2. During each period $n$, the equipment operates with a constant production rate $U_{n}$. Consequently, the risk function remains constant during each period. In this case, the vector $z(t)$, which represents the variable working conditions at each instant $t$ of period $n\left(t \in\left[T_{n-1}, T_{n}\right]\right)$, can be directly represented by the production rate $U_{n}$. Furthermore, the risk function over the period $n$ can be expressed as the ratio of $U_{n}$ to $U^{\max }\left(\Psi\left(U_{n}\right)=U_{n} / U^{\max }\right)$. If one considers that a perfect PM action is performed at the beginning of each period, then the failure rate function $\lambda_{n}(t)$ over period $n$ may be expressed as follows:

$$
\lambda_{n}(t)=\frac{U_{n}}{U^{\max }} \lambda_{0}(t), \quad \forall n \in[1, N], t \in\left[0, O T_{n}\right]
$$

3. But in our study, the equipment undergoes either an IPM action or a remanufacturing action at the beginning of each period. Therefore, Eq. (14) becomes:

$$
\lambda_{n}(t)=\left\{\begin{array}{ll}
\frac{U_{n}}{U^{\max }} \lambda_{0}(t) & \text { if } \sum_{q^{\prime}=0}^{N q-1} X_{q, n}=1 \\
\frac{U_{n}}{U^{\max }} A_{n} \lambda_{0}\left(b_{n} y_{n}+t\right) & \text { otherwise }
\end{array} \quad t \in\left[0, O T_{n}\right]\right.
$$

The first equation in the system of Eq. (15) refers to the equipment failure rate for the periods during which a remanufacturing action is performed, including the first period. It is important to recall that, after each remanufacturing action, the equipment is restored to an AGAN state, and is consequently brought back to age zero. Regarding the other periods, during which a PM action is performed, the second equation can be used to represent the failure rate. In this case:

$$
A_{n}=\prod_{j=P(n)+1}^{n} a_{j}
$$

- $P(n)$ denotes the period over which the last remanufacturing action is performed (if it exists) before the period $n$ (if any remanufacturing action occurs before the period $n$, then $P(n)$ is replaced by 1 ),

- $a_{j}$ is the HRIF which reflects the effect of the PM action, performed in period $j$, on the equipment failure rate.

- $y_{n}$ is the effective age of the equipment at the end of period $n-1$, and just before performing the PM action at period $n$ :

$$
\begin{aligned}
y_{n} & =O T_{n-1}+b_{n-1} y_{n-1} \\
& =O T_{n-1}+b_{n-1}\left(O T_{n-2}+b_{n-2} y_{n-2}\right) \\
& =O T_{n-1}+b_{n-1} O T_{n-2}+\ldots+\prod_{j=P(n)+1}^{n-1} b_{j} O T_{P(n)}
\end{aligned}
$$


- $b_{n}$ is the ARF which reflects the effect of the PM action, performed in period $n$, on the age of the equipment.

The system of Eq. (15) can be used only when the remanufacturing operations are performed by using spare parts having the same degradation pattern. However, in this work, remanufacturing is performed by using one of the various types of spare parts (new or remanufactured) having different degradation patterns (different failure rates). In reality, there is a high probability that the degradation of a remanufactured spare part be higher than that of a new one (see Diallo et al., 2014). To take into account this situation, let $\lambda_{0,0}(t)$ be the baseline failure rate function of a new equipment (new part) when operating under maximal production rate, and $\lambda_{0, q}(t)$ the failure rate function of an equipment that has a main part of quality $q$ when operating under the production rate $U^{\max }$. Therefore:

$$
\lambda_{0, q}(t)=r_{q} \lambda_{0,0}(t), \quad q \in[0, N q-1]
$$

Here, $r_{q}$ represents the failure rate multiplier factor relevant to the type of spare part used. This factor is used to designate the effect of the remanufacturing process on the returned parts. Consequently, the failure rate function $\lambda_{n}(t)$ during a specific period (Eq. 15) can be expressed as follows:

$$
\lambda_{n}(t)=\left\{\begin{array}{ll}
\frac{U_{n}}{U^{m a x}} \lambda_{0, q}(t) & \text { if } \sum_{q^{\prime}=0}^{N q-1} X_{q, n}=1 \text { and } Y_{q, n}=1 \\
\frac{U_{n}}{U^{m a x}} A_{n} \lambda_{0, q}\left(b_{n} y_{n}+t\right) & \text { if } \sum_{q^{\prime}=0}^{N q-1} X_{q, n}=0 \text { and } Y_{q, n}=1
\end{array} \quad t \in\left[0, O T_{n}\right], q \in[0, N q-1]\right.
$$

Fig. 2 displays the variation of the failure rate when IPM actions and remanufacturing operations are performed.

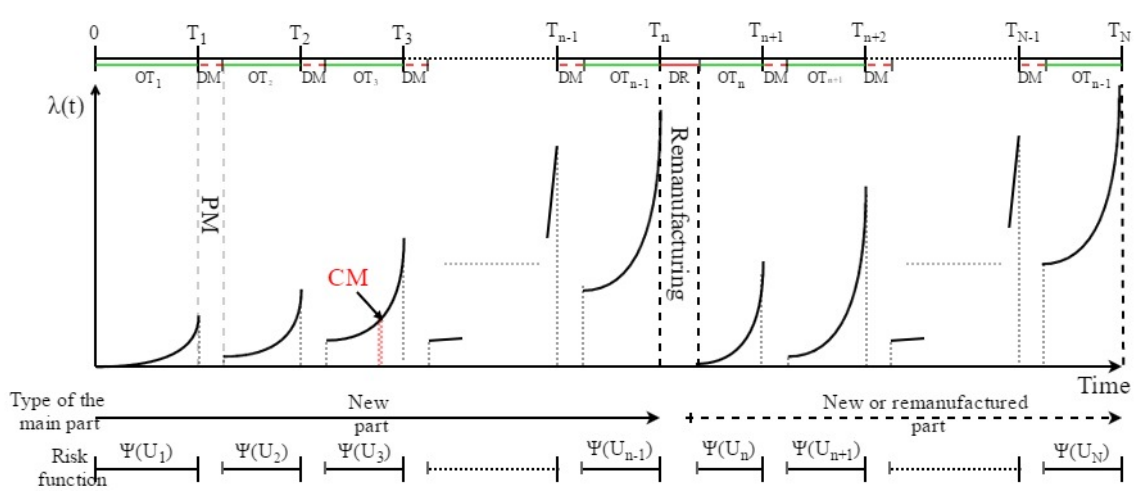

Fig. 2. An example of imperfect maintenance with a remanufacturing plan

\subsection{Depreciation model}

Any equipment is subject to a decline in value (depreciation) during its useful life due to its age and usage. One possible approach to estimate the depreciation value is to use a method that is acceptable under International Accounting Standards (IAS 16), such as the straight line depreciation method, the reducing balance depreciation method or the activity-based depreciation method. However, these models suppose that the economic life of an equipment is known, and its value diminishes with time or usage (Grover and Grover, 2015). The IAS 16 states that the most appropriate method to estimate the depreciation expense of an asset should reflect the expected pattern of its consumption. For example, the straight line depreciation method 
seems consistent with a constant operating mode. This method is the most frequently used by companies all around the world (Marzo and Pagnozzi, 2011).

The equipment considered in the present study is used in different manners over the production horizon, depending on the variation of demands. Consequently, the depreciation expense differs from one period to another, depending on the number of units produced per period; therefore, it is a function of the operating time and production rate. In this case, the use of the straight line depreciation method cannot reflect the real consumption pattern. One possible alternative method, which seems consistent with the studied problem, is the activity-based depreciation approach (known also as the units of production method (UPM)) which makes it possible to estimate the depreciable amount of an asset according to its use. According to Palmer and Davis (2004), the time-of-use is the most popular single activity factor prescribed by proponents of activitybased costing $(\mathrm{ABC})$ in machine-intensive environments. However, the units of time are not equal. Note that "Intensity" is one factor that can modify the impact of the operating time on depreciation. The intensity of use is commonly referred to as the "Load"; it is defined as a multiple of the speed and feed rates at which an operation is performed. For example, a machine operating at higher than normal prescribed speed and feed rates is a driver of inordinate consumption.

By analyzing these two factors, i.e. time and intensity, one can say that both of them cannot reflect the consumption pattern of the studied equipment, if each factor is considered separately. The reason is that both of the operating time and intensity (production rate) are different in each period. To deal with this situation, and based of the study of Palmer and Davis (2004), a new version of the activity-based depreciation approach is proposed; in this version, the production intensity factor is combined with the operating time in order to address the weaknesses of the depreciation allocation model that is based only on the operating time or production intensity.

Before explaining the proposed depreciation model, it is worth recalling that the value of the durable parts is constant and is not taken into consideration. In this case, the equipment's value is represented only by that of its core (main part).

Based on the modified activity-based approach, the expected depreciation value during a production period $n$ can be estimated by the following expression:

$$
\operatorname{Depr}_{n}=\sum_{q=0}^{N q-1}\left(Y_{q, n} K_{n} \text { Deprate }_{q}\right) U_{n} O T_{n}, \quad \forall n \in[1, N]
$$

where Deprate $_{q}$ denotes the average depreciation rate when the main part is of type $q\left(Y_{q, n}=1\right)$ and the production is intensive. It can be calculated as follows:

$$
\text { Deprate }_{q}=\frac{A C_{q}-S V_{q}}{T P U_{q}}, \quad \forall q \in[0, N q-1]
$$

In this model, it is assumed that, whatever the type of the installed part $q$, the residual value $S V_{q}$ of the equipment after producing $T P U_{q}$ units under a constant production rate $U^{\max }$ is equal to zero. Moreover, $K_{n}$ is an adjustment factor that is used to reflect the effect of the production intensity in period $n$ on the depreciation 
expense pattern:

$$
K_{n}=\left\{\begin{array}{ccc}
\alpha & \text { if } U_{n} \in[0, v 1[ & \text { Moderate production rate } \\
\beta \quad \text { if } U_{n} \in[v 1, v 2[ & \text { High production rate } \\
1 \quad \text { if } U_{n} \in\left[v 2, U^{\max }\right] & \text { Intensive production rate }
\end{array} \quad \forall n \in[1, N]\right.
$$

where $\alpha$ and $\beta(0<\alpha<\beta<1)$ are two values determined by the OEM.

It is important to note that the value of the equipment after each remanufacturing action is improved after the installation of the spare part; its expected salvage value $V_{n}$ at the end of the $n^{\text {th }}$ period can be obtained simply by subtracting the depreciation expense $D e p r_{n}$ from its expected value at the beginning of the same period:

$$
V_{n}=\sum_{q=0}^{N q-1}\left(X_{q, n} A C_{q}\right)+\left(1-\sum_{q=0}^{N q-1} X_{q, n}\right) V_{n-1}-\operatorname{Depr}_{n}, \quad \forall n \in[1, N]
$$

\section{Solution approach}

The integrated production and remanufacturing planning model proposed in this work is a mixed nonlinear programming model that belongs to the class of NP-hard problems. Solving this problem analytically, exhaustively or by using a commercial tool is too difficult, even for small problems, is not efficient with respect to the fixed objectives. For this reason, it was decided to solve it by means of a hybrid genetic algorithm (HGA). Genetic algorithms are the most popular types of metaheuristics due to their performance in solving complex problems, to their simplicity and ease of hybridization with other methods. These algorithms can also be successfully applied to a very wide range of problems. The developed HGA incorporates a Fix-and-Relax based rolling-horizon (FRRH) heuristic. To the best of our knowledge, very few papers have attempted to combine these two popular FR and RH heuristics despite the fact that they are primarily used for lot-sizing and scheduling problems (see Beraldi et al. 2008; Clark 2005; Dillenberger et al. 1994).

Fig. 3 illustrates the general scheme of our solution approach. The integrated solution approach aims mainly at jointly exploring different solutions. The primary idea is to investigate the different possibilities of the remanufacturing plan using the genetic algorithm. Then, for each possibility, the FRRH heuristic is used to obtain the production plan. Finally, the fitness of each production/remanufacturing plan is investigated and evaluated in order to determine the best one.

\subsection{Genetic algorithm}

The genetic algorithm proposed here is based on a single population approach, when each individual (chromosome) represents a possible solution to the remanufacturing plan. The first step consists of defining the encoding method. Our chromosome is a vector of size $N$ (number of periods), where each gene $n(n \leq N)$ contains information about the type of operation (maintenance or remanufacturing) that must be performed at the relevant period $n$ (see Fig. 4). This information is represented by an integer number between 0 and 2 Nq-1. If this number is equal to one possible value of $q(0,1, \ldots, \mathrm{Nq}-1)$, then a remanufacturing operation must take place during that period using a spare part of quality $q\left(X_{q, n}=1\right)$; otherwise, only a maintenance action must be performed $\left(\sum_{q=0}^{N q-1} X_{q, n}=0\right)$. 


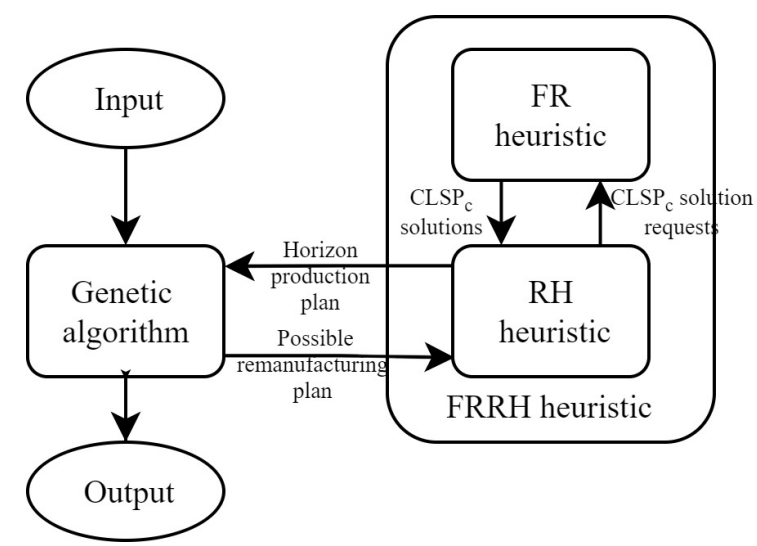

Fig. 3. Scheme of the proposed hybrid genetic algorithm (HGA)

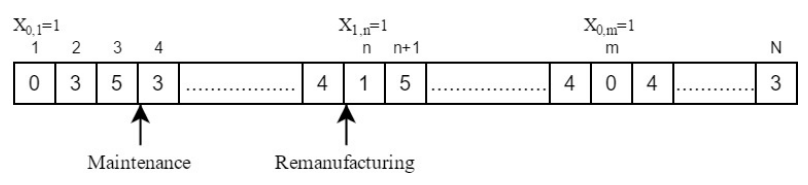

Fig. 4. Chromosome structure $(N q=3)$

Now, the different steps of the proposed GA are explained bellow:

1. Generate randomly an initial population of $N B$ chromosomes.

2. Create two matrix A and B with $N B$ lines and $N$ columns.

3. Use the FRRH heuristic to obtain a production plan for each chromosome.

4. Evaluate the fitness of each chromosome based on its production and remanufacturing plans, then sort and record them in the decreasing order of their fitness in the matrix A.

5. Record the first chromosome of matrix A in a vector bestsol.

6. Repeat the following steps until reaching the stop criterion (see Fig. 5):

(a) Record the first $p r$ chromosomes of A in B (i.e. keep the best parents for the next iteration) (arrow $1)$.

(b) Selection: employ the wheel selection mechanism to select $(1-p r)$ parents from the matrix A for the crossover operator (arrow 2).

(c) Crossover: let $p_{c}$ be the crossover probability. For each pair of the selected parents (the first with the second, the third with the fourth, and so on), generate a random number $r$ between 0 and 1 . If $r<p_{c}$, the present pair is crossed using a random one-point crossover method to create two new offspring which replace their parents, otherwise, no crossover is performed, and the considered pair keeps its position. By applying this method, the size of the crossed population remains $(1-p r)$ (arrow 3).

(d) The FRRH heuristic is used to obtain the production plan for each offspring created by the crossover operator and then evaluate the fitness of that offspring.

(e) Sort the chromosomes resulting from (c) in the decreasing order (arrow 3) and add them to B (arrow 4) to avoid any destruction of good chromosomes by the mutation operator.

(f) Mutation: let $p_{m}$ be the mutation probability. For each chromosome resulting from (e), generate a random number $r$, between 0 and 1. If $r<p_{m}$, the chromosome will undergo an inversion mutation 
by inverting the values of two random genes; otherwise, no mutation is applied to this chromosome (arrow 5). Let $N_{m}$ be the number of the mutated chromosomes. These chromosomes are recorded in matrix B by crushing its last $N_{m}$ chromosomes (arrow 6).

(g) Use the FRRH heuristic to obtain the production plan for the mutated chromosomes, and then evaluate their fitness.

(h) Initialize the matrix A.

(i) Sort, in decreasing order, the chromosomes of matrix B in the initialized matrix A (arrow 7), record the first chromosome in a vector bestnew, then initialize the matrix B.

(j) If the bestnew solution is better than the bestsol solution, then get bestsol = bestnew.

(k) If the stopping condition (a predefined number of iterations $i$ without improving the best solution) is reached, stop, and return bestsol; otherwise, go to step (a).

A correction procedure is applied to satisfy the non-respected constraints, when an infeasible chromosome is created either by initialization, crossover or mutation operators.

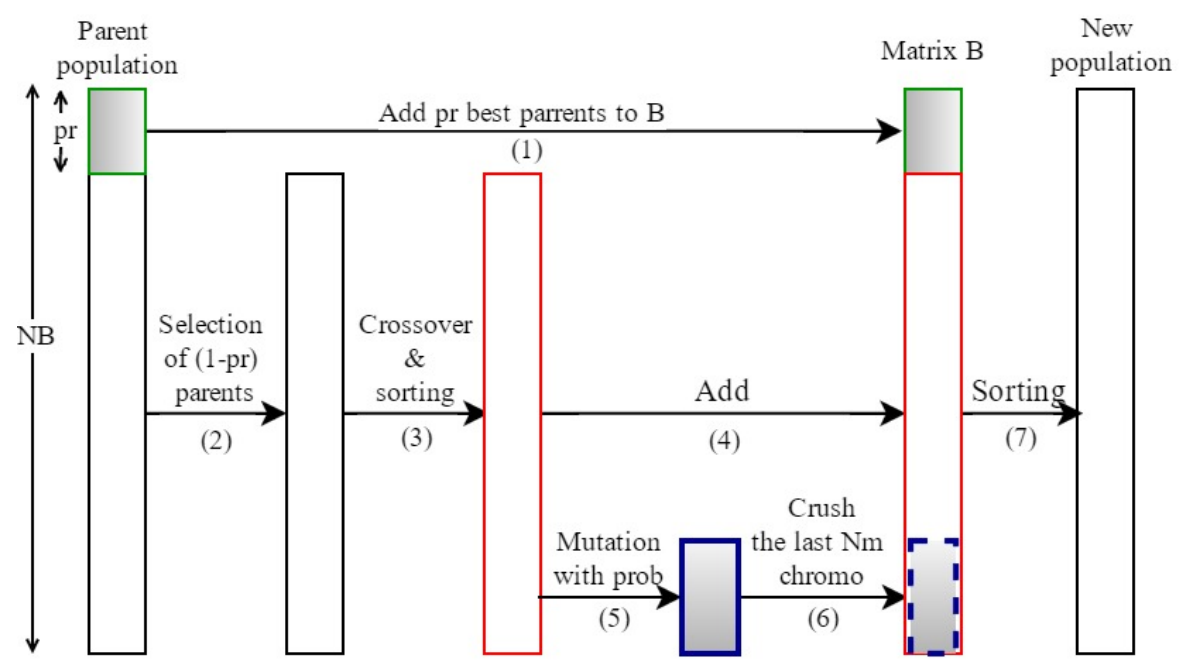

Fig. 5. The genetic algorithm operators

\subsection{Fix-and-Relax based rolling horizon heuristic (FRRH)}

This section tends to present the proposed FRRH heuristic to solve the production problem. The aim is to find the optimal production plan that allows minimizing the total holding costs, maintenance costs and depreciation costs. Various types of lot-sizing problems are found in the literature. The reader may refer to Glock et al. (2014); Karimi et al. (2003). In this work, the demands are assumed to be deterministic and dynamic. In addition, the capacity of the equipment is restricted. Therefore, the production problem treated here may be considered as a capacitated lot-sizing problem $(C L S P)$.

The proposed FRRH is a combination of two approaches frequently used to solve $C L S P$ problems, namely the Rolling-Horizon (RH) approach and the Fix-and-Relax (FR) approach.

The RH approach is dedicated to solve a CLSP problem by dividing it into $C$ sub-problems $C L S P_{c}(c=$ $1, \ldots, C)$. Each one corresponds to an interval $\left[f_{c}, l_{c}\right]$, such that $f_{1}=1, f_{c}=l_{c-1}+1$ and $l_{C}=N$ (see Fig. 6). This method is suitable when product demands are deterministic (known in advance) or are gradually revealed during the planning horizon (Beraldi et al., 2008). The implementation of the RH concept is designed in such 
a way that sub-problems $C L S P_{c}$ are always feasible if the $C L S P$ problem is feasible. In our study, a $C L S P$ problem is feasible if and only if the equipment can satisfy all demands at its delivery time.

However, the FR approach is a constructive/iterative approach used to gradually solve CLSP problems (Tempelmeier and Copil, 2016). This approach starts by setting an "observation window (OW)" of size $\sigma$ periods. In the first step, this window covers the first $\sigma$ periods; the original model is considered only for this window, while it is relaxed for all subsequent periods represented by a second window called the "approximation window (AW)". Then, at each step $k$ :

- (i) The OW is shifted $\delta$ periods ahead (towards the future);

- (ii) The results obtained for the periods before the OW are fixed (this set of periods can be represented by a third window called the "fixed window (FW)");

- (iii) The original model is then applied only to the observation window, while it is relaxed for the approximation window, so that the results, obtained for the periods that are in the intersection (overlapping interval) between the observation window of step $k-1$ and that of step $k$, can be modified (see Fig. 7).

This procedure is repeated until reaching the end of the planning horizon.

Regarding the genetic algorithm, when a new possible solution of remanufacturing plan is generated by one of its operators (initialization, crossover, mutation), a new decomposition of the production horizon into $C$ production cycles is proposed. In this step, the $\mathrm{RH}$ approach is applied to divide the whole CLSP problem into separate feasible $C L S P_{c}$ sub-problems. Then, for each sub-problem, the FR approach is applied to gradually obtain the production plan of cycle $c$. Fig. 6 and 7 illustrate the principle of the proposed FRRH heuristic, while its pseudo-code is given in the Appendix.

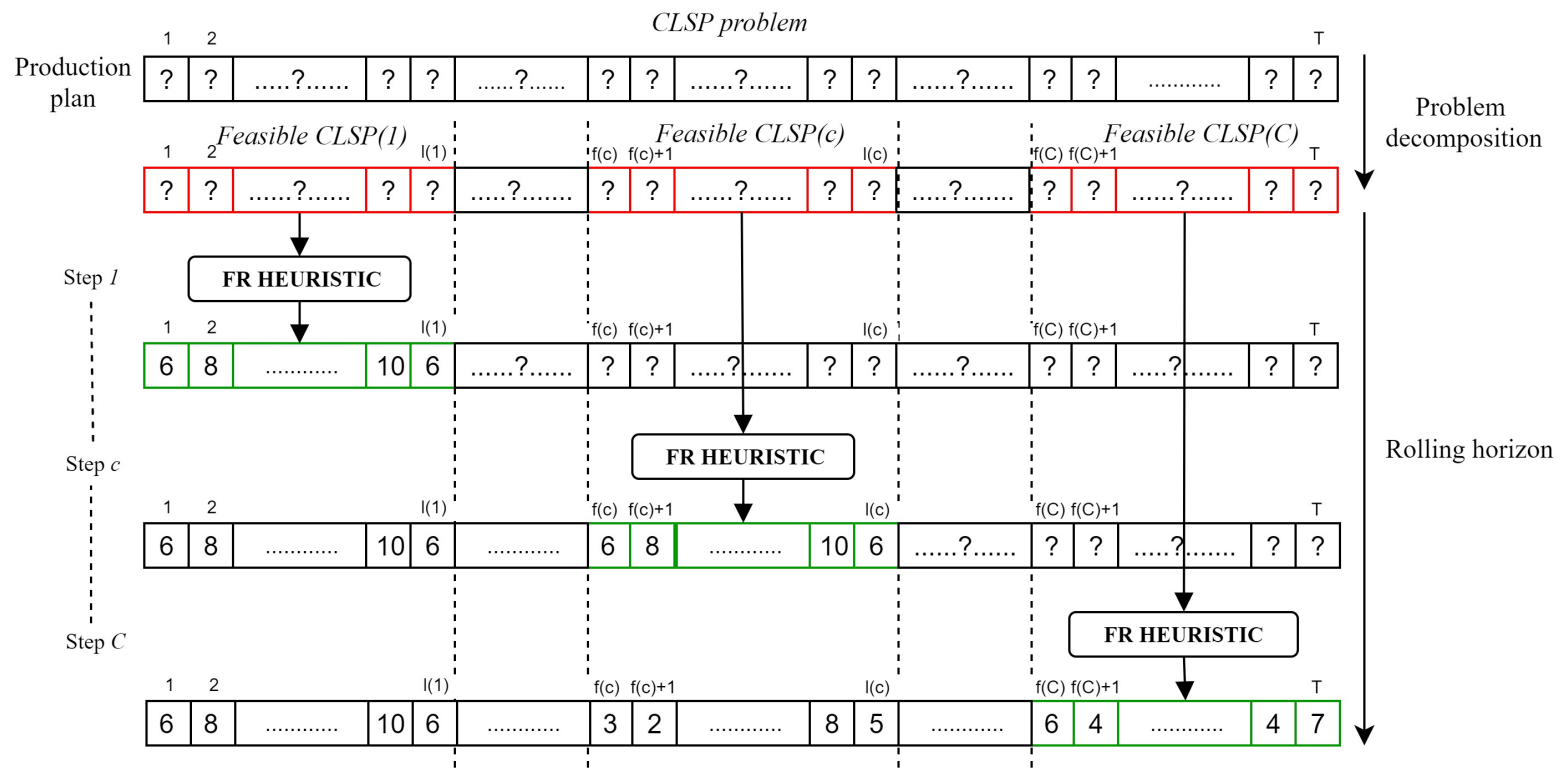

Fig. 6. Rolling horizon (RH) approach 


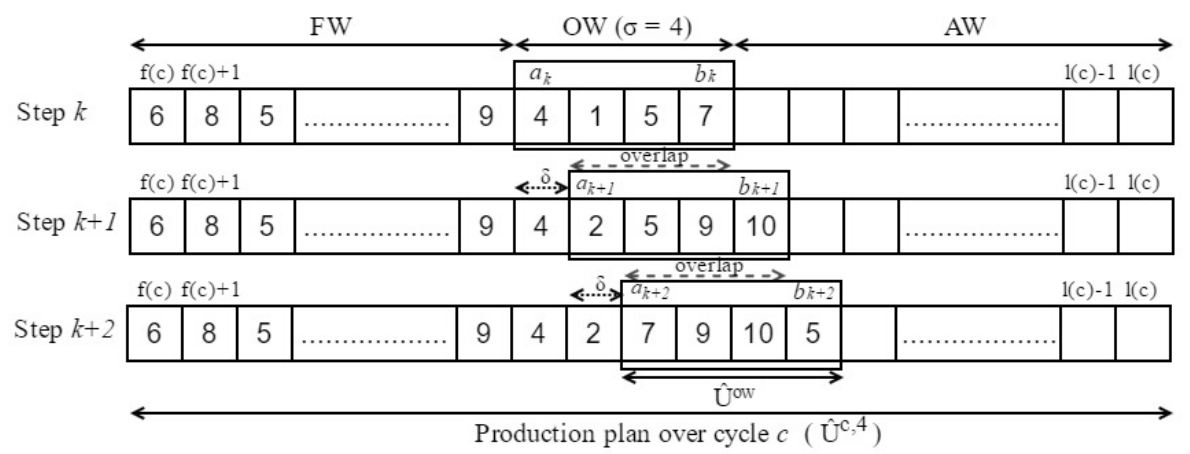

Fig. 7. Fix-and-Relax (FR) approach $(\sigma=4, \delta=1)$

\subsubsection{CLSP $P_{c}$ sub-problem model}

Let $f_{c}$ and $l_{c}$ be the first and last periods in the cycle $c$, and $q_{c}$ the type of main part used over this cycle $\left(X_{q_{c} f_{c}}=1\right)$. Each $C L S P_{c}$ sub-problem can be expressed as follows:

$$
C L S P_{c}: \text { Minimize } T C_{f_{c}, l_{c}}^{c}=\sum_{n=f_{c}}^{l_{c}}\left(C_{n}+h . S_{n}+D e p r_{n}\right)
$$

Subject to:

$$
\begin{gathered}
S_{n}=S_{n-1}+U_{n} O T_{n}-D_{n}, \quad \forall n \in\left[f_{c}, l_{c}\right] \\
U_{n} \leq U^{\max }, \quad \forall n \in\left[f_{c}, l_{c}\right] \\
V_{n} \geq 0, \quad \forall n \in\left[f_{c}, l_{c}\right]
\end{gathered}
$$

The objective function (1) is simplified to (24) by replacing the third, fourth and fifth terms by the total depreciation expense; it is next applied only to cycle $c\left(\left[f_{c}, l_{c}\right]\right)$. Constraints $(25),(26)$ and $(27)$ are identical to constraints (3), (4), and (5), respectively, but they are applied only to cycle $c$.

To evaluate the maintenance cost in cycle $c$, the same equations, i.e. Eq. (8) to Eq. (10), are used but only on the interval $\left[f_{c}, l_{c}\right]$. However, Eqs. (11) and (19) can be simplified respectively to Eqs. (28) and (29) as follows:

$$
\begin{aligned}
& D T_{n}=\left\{\begin{array}{ll}
D R & \text { if } n=f_{c} \\
D M & \text { otherwise }
\end{array} \quad \forall n \in\left[f_{c}, l_{c}\right]\right. \\
& \lambda_{n}(t)=\left\{\begin{array}{ll}
\frac{U_{n}}{U^{m a x}} \lambda_{0, q_{c}}(t) & \text { if } n=f_{c} \\
\frac{U_{n}}{U^{\max }} A_{n} \lambda_{0, q_{c}}\left(b_{n} y_{n}+t\right) & \text { otherwise }
\end{array} \quad t \in\left[0, O T_{n}\right], n \in\left[f_{c}, l_{c}\right]\right.
\end{aligned}
$$

With regard to depreciation expenses, Eqs. (20) and (23) can be simplified to (30) and (31), respectively:

$$
\operatorname{Depr}_{n}=K_{n} \text { Deprate }_{q_{c}} U_{n} O T_{n}, \quad \forall n \in\left[f_{c}, l_{c}\right]
$$




$$
V_{n}=\left\{\begin{array}{ll}
A C_{q_{c}}-\text { Depr }_{n} & \text { if } n=f_{c} \\
V_{n-1}-\text { Depr }_{n} & \text { otherwise }
\end{array} \quad \forall n \in\left[f_{c}, l_{c}\right]\right.
$$

In the case where no solution is found for one of the $C L S P_{c}$ sub-problems (for example, no solution satisfies

the constraint of demand), the current remanufacturing solution proposed by the GA is infeasible and must be corrected by updating the chromosome genes.

\section{Numerical experiments}

To illustrate the applicability of the proposed approach, a production horizon composed of $N=36$ months and characterized by different demands (Table 1) is considered. Three types of spare parts with different parameters are considered (see Table 2.a, where $m u$ denotes the "monetary units"). The degradation parameters can be provided by the maintenance service. Here, the baseline failure rate (when using a new part under maximal production rate) is defined by a Weibull distribution with a scale parameter 3 and a shape parameter $110\left(\lambda_{0,0}(t)=(3 / 110) \times(t / 110)^{2}\right)$. Parameters related to the imperfect preventive maintenance $($ ARF, HRIF, duration and cost) are given in Table 2.b. Table 2.c contains $K_{n}$ values based on the production rate intensity. The remaining parameters are given in Table 2.d.

. Table 3 contains the best parameters of the hybrid genetic algorithm (HGA), obtained after several tests.

Table 1: The average monthly demand

\begin{tabular}{lllllllllllll}
\hline & Jan & Feb & Mar & Apr & May & Jun & Jul & Aug & Sep & Oct & Nov & Dec \\
\hline Year 1 & 160 & 200 & 230 & 270 & 240 & 180 & 240 & 190 & 100 & 220 & 200 & 220 \\
Year 2 & 200 & 290 & 260 & 220 & 230 & 380 & 220 & 240 & 200 & 190 & 180 & 140 \\
Year 3 & 130 & 110 & 100 & 120 & 100 & 135 & 120 & 90 & 90 & 140 & 130 & 90 \\
\hline
\end{tabular}

Table 2: Problem parameters

(a) Spare part parameters

\begin{tabular}{llll}
\hline$q$ & $A C(m u)$ & $r$ & Deprate \\
\hline 0 & 50000 & 1 & 10 \\
1 & 32000 & 1.09 & 9.86 \\
2 & 25000 & 1.2 & 9.72 \\
\hline
\end{tabular}

(c) Depreciation adjustment factor (b) IPM parameters

\begin{tabular}{llll}
\hline Failure rate & $C P M$ & $a$ & $b$ \\
\hline$\lambda<0.003$ & 300 & 1.1 & 0.2 \\
$0.003 \leq \lambda<0.006$ & 400 & 1.15 & 0.25 \\
$\lambda \geq 0.006$ & 500 & 1.17 & 0.35 \\
\hline
\end{tabular}

(d) Remaining parameters

\begin{tabular}{ll}
\hline Production intensity & $K_{n}$ \\
\hline$U_{n}<6$ & 0.6 \\
$6 \leq U_{n}<8$ & 0.8 \\
$8 \leq U_{n} \leq U^{\max }$ & 1 \\
\hline
\end{tabular}

\begin{tabular}{llllll}
\hline$U^{\max }$ & $D M$ & $D R$ & $C C M$ & $h$ & $C^{r e p}$ \\
\hline 10 & 3 days & 6 days & $3000 \mathrm{mu}$ & $5 \mathrm{mu}$ & $5000 \mathrm{mu}$ \\
\hline
\end{tabular}


Table 3: HGA parameters

\begin{tabular}{lllll}
\hline$N B$ & $i$ & $p r$ & $p_{c}$ & $p_{m}$ \\
\hline 100 & 100 & 10 & 0.9 & 0.1 \\
\hline
\end{tabular}

Fig. 8 summarizes the results obtained. It presents the best production and remanufacturing plans obtained with a total cost equal to $8.57 \times 10^{4} \mathrm{mu}$.

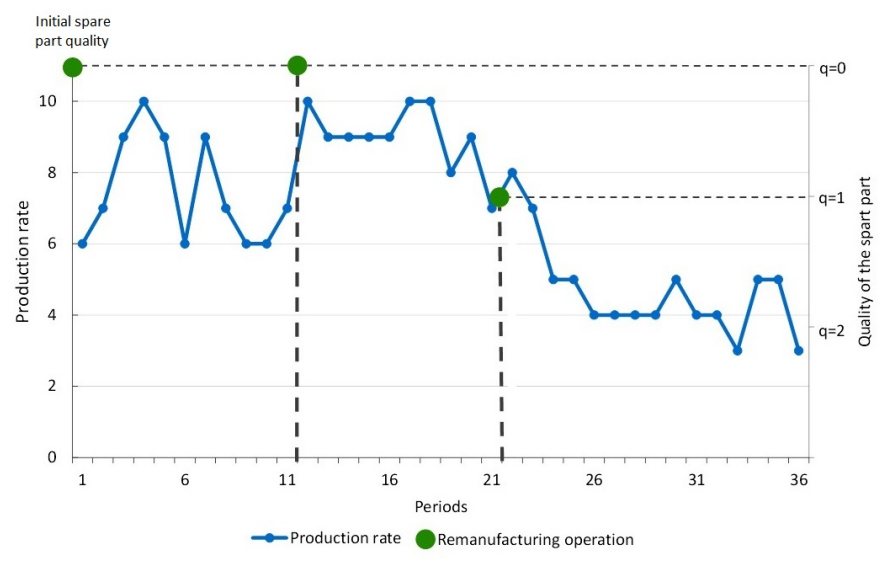

Fig. 8. Near-optimal production/remanufacturing plan

The results obtained here allow noting that the equipment must be remanufactured for the first time after

11 operating periods. The best production rate during this cycle varies between high and intensive; it takes a minimal value equal to 6 and a maximal value equal to $U^{\max }$. The remanufacturing plan is justified by the failure rate level reached at period 11 (see Fig. 11) where it is economically preferable to remanufacture the equipment in order to halt the excessive increase in the maintenance cost and the depreciation expense, which are clearly observed in Fig. 9 and 10, respectively.

Regarding the selection of spare parts, the analysis of the data in Table 1 allows us to note that the periods following period 11 are characterized by high demands. These demands force the equipment to operate intensively over those periods; it is therefore preferable to choose a new spare part $(q=0)$ for the remanufacturing process in order to ensure a high performance level that is consistent with the nature of the following operating conditions.

Based on the results of the second cycle, the equipment must operate intensively at the beginning and at the middle of this cycle during which the production rate reaches the maximal value $U^{\text {max }}$ three times. Hence, this operation mode yields a faster increase in the failure rate and in the maintenance cost as well. However, after period 18 , the production rate starts decreasing. Nevertheless, the failure rate continues to grow, due to the combined effect of both: (i) the IPM and (ii) the intensive use over the periods proceeding this cycle.

This failure rate increase engenders high maintenance costs. Consequently, a second remanufacturing operation must be performed at the beginning of period 22. In this case, the spare part to be selected is of type "remanufactured", due to the nature of the next production rate which takes a moderate value as compared to the previous production cycles. In regard to the degradation pattern over this cycle, a significant difference in the failure rate level is clearly noted during this cycle as compared to that of the previous cycles. This difference evidently confirms the impact of the production intensity on the equipment's general condition. 
Regarding the value of the equipment (represented by the value of its main part), analysis of Fig. 8 and 10 allows observing a significant correlation between the production rate and the depreciation expense. When comparing two different cycles, such as cycle 1 and cycle 2, one can notice that the value of the equipment increases faster with the rising production intensity. In the first cycle, the equipment value decreases until it reaches a salvage value equal to almost $30000 \mathrm{mu}$, after 11 periods of use; however, at the end of the second cycle, the salvage value reaches almost $25000 \mathrm{mu}$, after only 10 periods. This pattern is due to the higher production intensity over the second cycle (between 8 and 10 products/tu) as compared to that of the first cycle (between 6 and 10 products $/ t u$ ).

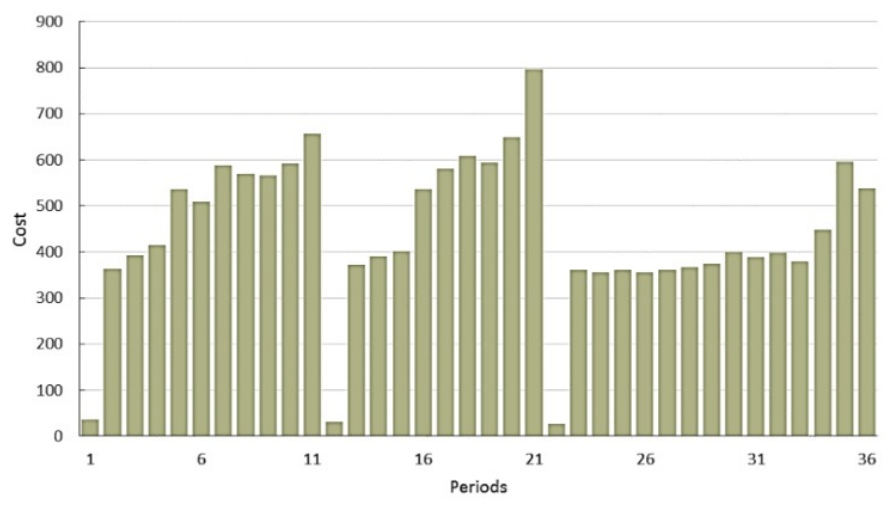

Fig. 9. Maintenance cost per period

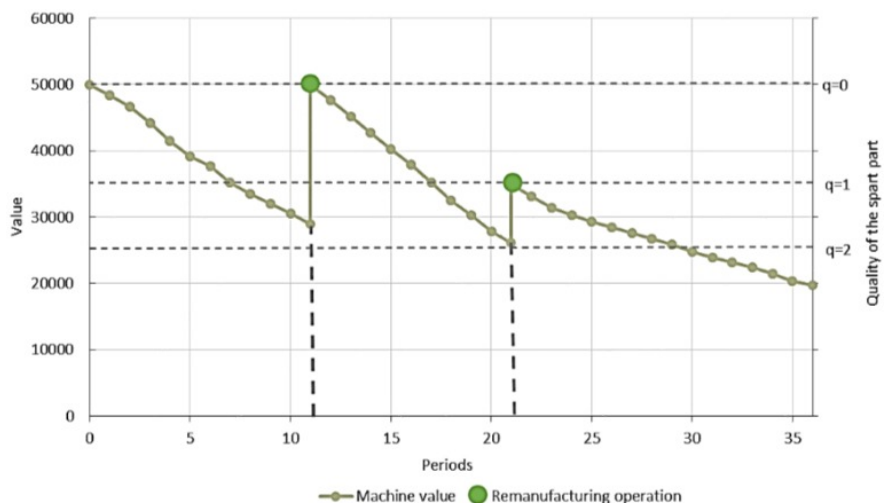

Fig. 10. Equipment value 


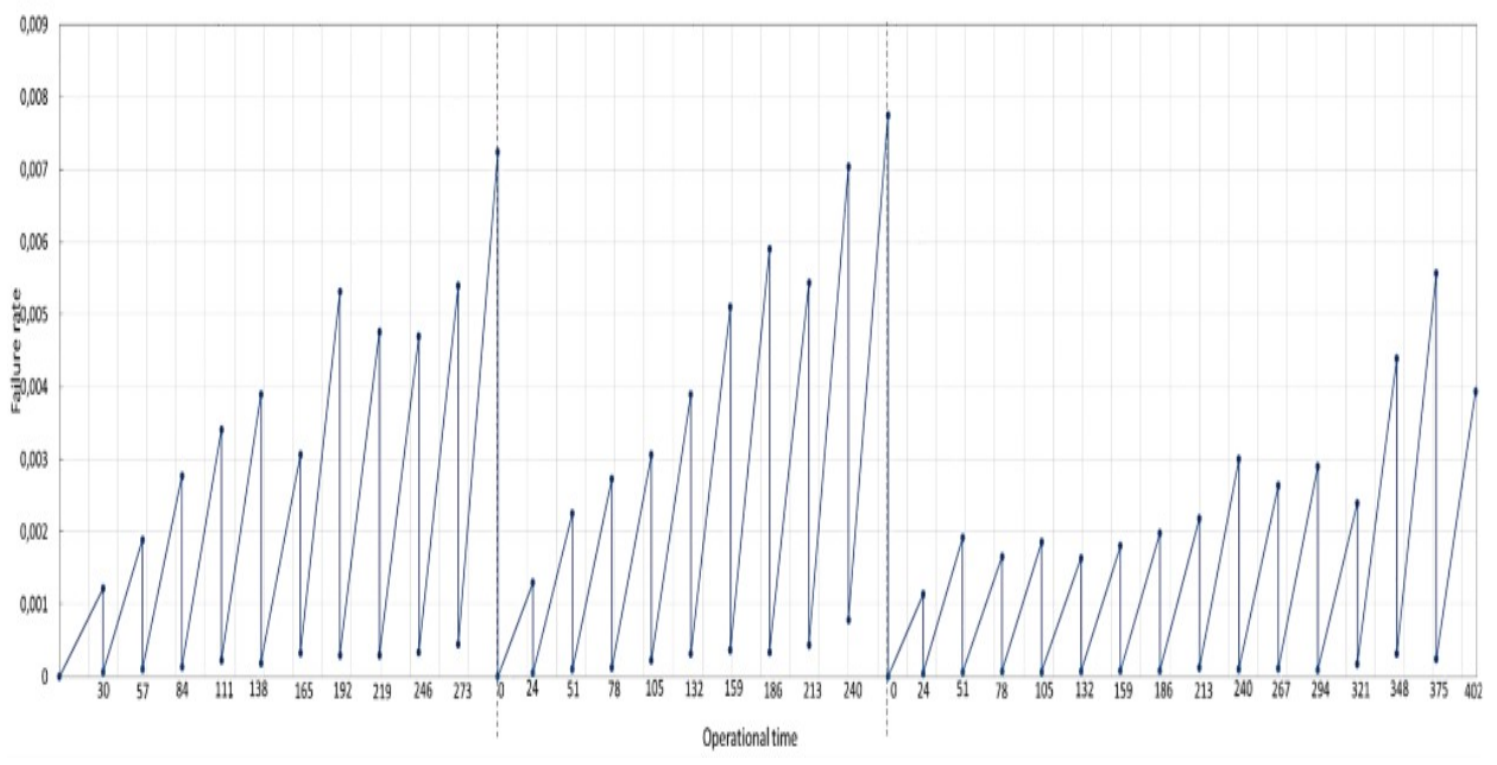

Fig. 11. Failure rate over the production horizon

\section{Sensitivity analysis}

\subsection{Effect of demand variations on the production and remanufacturing plans}

The previous section focused on the analysis of an example where the demands varied between high, medium and low, throughout the same planning horizon. In this same section, three scenarios are compared. In each scenario, the equipment used is supposed to meet a homogeneous demand (high, medium or low) during the planning horizon. The objective sought is to analyze the impact of demand variations on the remanufacturing plan. Fig. 12 illustrates the requested demand for each scenario; in the first one, the equipment is used to meet high demands; in the second scenario, it is used to satisfy medium demands; while in the third scenario, it is used to meet low demands.

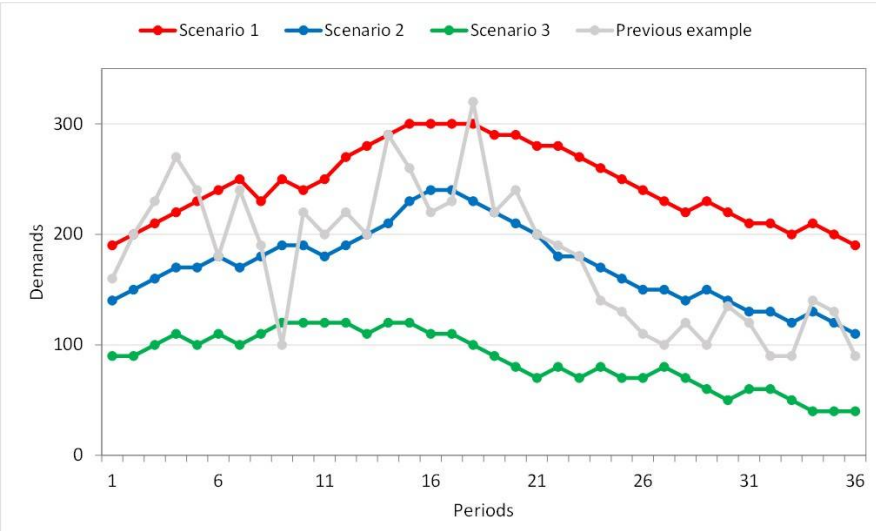

Fig. 12. Requested demands for each scenario

Fig. 13 illustrates the results obtained for the three cases. To meet the received demand, the production intensity must vary:

- In situation 1: between 7 and 10 products/day,

- In situation 2: between 4 and 9 products/day,

- In situation 3: between 1 and 5 products/day. 
The first observation to make is about the high demands corresponding to higher values of the production rate. The second one relates to the fact that in scenario 1, demands in periods 13 to 22 exceed the equipment production capacity (270 products per period); therefore, the storage of manufactured products during the previous periods is necessary in order to avoid the inventory shortage, even if the storage costs are high.

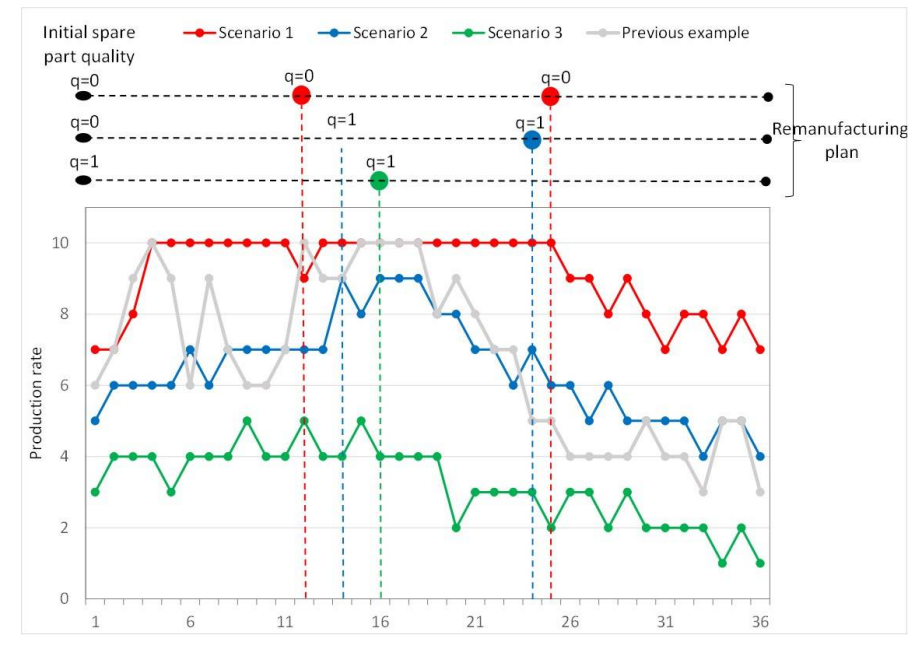

Fig. 13. The effect of demand variations on the production and remanufacturing plans

To ensure these operating conditions with minimal cost, the equipment in scenarios 1 and 2 must be new (contain a new main part) at the beginning of the planning horizon; moreover, it is preferable to remanufacture the equipment twice. For scenario 1, it is remanufactured at period 12 (the first time), and at period 25 (the second time). For scenario 2, the equipment is remanufactured at period 14 (the first time), and at period 24 (the second time).

For scenario 3, it starts operating with a remanufactured part from the beginning. This part is replaced once at period 16 . observations can be made:

- About the timing of remanufacturing actions: One can see that the remanufacturing actions take place early, when the equipment operates intensively (scenario 1). However, when the production intensity is low, it is preferable to delay the remanufacturing action, even if the initial used part is "remanufactured" (scenario 3).

- About the quality of the remanufacturing process: The intensity of production accomplished by the equipment in scenario 1 over the entire horizon requires the use of new spare parts. However, in scenario 3 , in which the equipment is used under low operating conditions, it is economically more desirable to use a remanufactured spare part instead of a new one (in order to take advantage of the remanufactured spare part's lower price).

However, in scenario 2, two solutions (remanufacturing plans) deserve being mentioned. According to the first solution (the best one), presented in Fig. 13, a remanufactured spare part $(q=1)$ is selected for the remanufacturing process at periods 14 and 24 . For the second solution, a new part is selected at period 
14 and a remanufactured one $(q=1)$ is selected at period 24 .

Based on this observation, and with reference to the previous example, it can be deduced that when the next average production rate is under 6 products/day, it is preferable to select a remanufactured part, and when it is above 8 products/day, a new part is required. Similarly, in the case where that rate varies between 6 and 8 products/day, both new and remanufactured parts $(q=1)$ can be used.

\subsection{Effect of the spare part's failure rate on the remanufacturing plan}

In this subsection, an attempt is made to analyze the effect of the spare part's deterioration on the total life cycle cost. Only one type of remanufactured spare parts is considered in order to conduct a clearer and more intelligible analysis. All parameters are kept fixed, except $r_{1}$, in order to analyze the change in the remanufacturing decisions as $r_{1}$ increases (it is worth recalling that $r_{q}$ represents a failure rate multiplier factor relevant to the type of part used; here, $q=1$ ). Demands and fixed parameter values are already given in Tables 1 and 2. Our numerical experiments in this subsection are conducted for different $r_{1}$ values, ranging from 1 to 1.15 .

Table 4 illustrates the change in the selected spare part and the increase in the total cost as $r_{1}$ rises. When $r_{1} \leq 1.01$ the user considers the new and the remanufactured spare parts almost identical in terms of reliability. However, in the present analysis, the results show that it is economically preferable to select a remanufactured part at each remanufacturing time. This is due to the fact that the depreciation rate of a remanufactured part is lower than that of a new one $\left(\right.$ Deprate $_{1}<$ Deprate $\left._{0}\right)$.

When $1.01<r_{1}<1.09$, a new part must be selected only when the operating conditions go to intense (period 12). However, $r_{1} \geq 1.09$, then the deterioration rate of a remanufactured part, when it is operating under maximal production rate, is higher than that of a new one by at least $8 \%$. In this case, only new parts must be selected to perform the remanufacturing operations. Therefore, it is obvious that $r_{1}=1.09$ is the threshold from which the choice of a remanufactured part is not recommended.

Table 4: The effect of $r_{1}$ on the remanufacturing plan

\begin{tabular}{cccc}
\hline$r_{1}$ & {$[1,1.01]$} & {$[1.02,1.09[$} & {$[1.09,1.15]$} \\
\hline TC & {$[84978,85021]$} & {$[85380,85768[$} & 85768 \\
Reman timing & $0-12-22$ & $0-12-22$ & $0-12-22$ \\
Reman quality & Reman parts & Reman part - New part - Reman part & New parts \\
\hline
\end{tabular}

\subsection{Effect of a spare part's depreciation on the remanufacturing plan}

All inputs are held constant, except $A C_{1}$ and $T P U_{1}$. Table 5 illustrates the near-optimal total cost for different Deprate $_{1}$ values. The main remark to be made is that when Deprate $_{1}$ exceeds Deprate De $_{0}$ (i.e. Deprate $_{1} \geq 10$ ), the remanufactured spare part is not recommended even if its acquisition price is the lowest (see the cells with blue text). 
Table 5: The effect of Deprate 1 on the remanufacturing plan

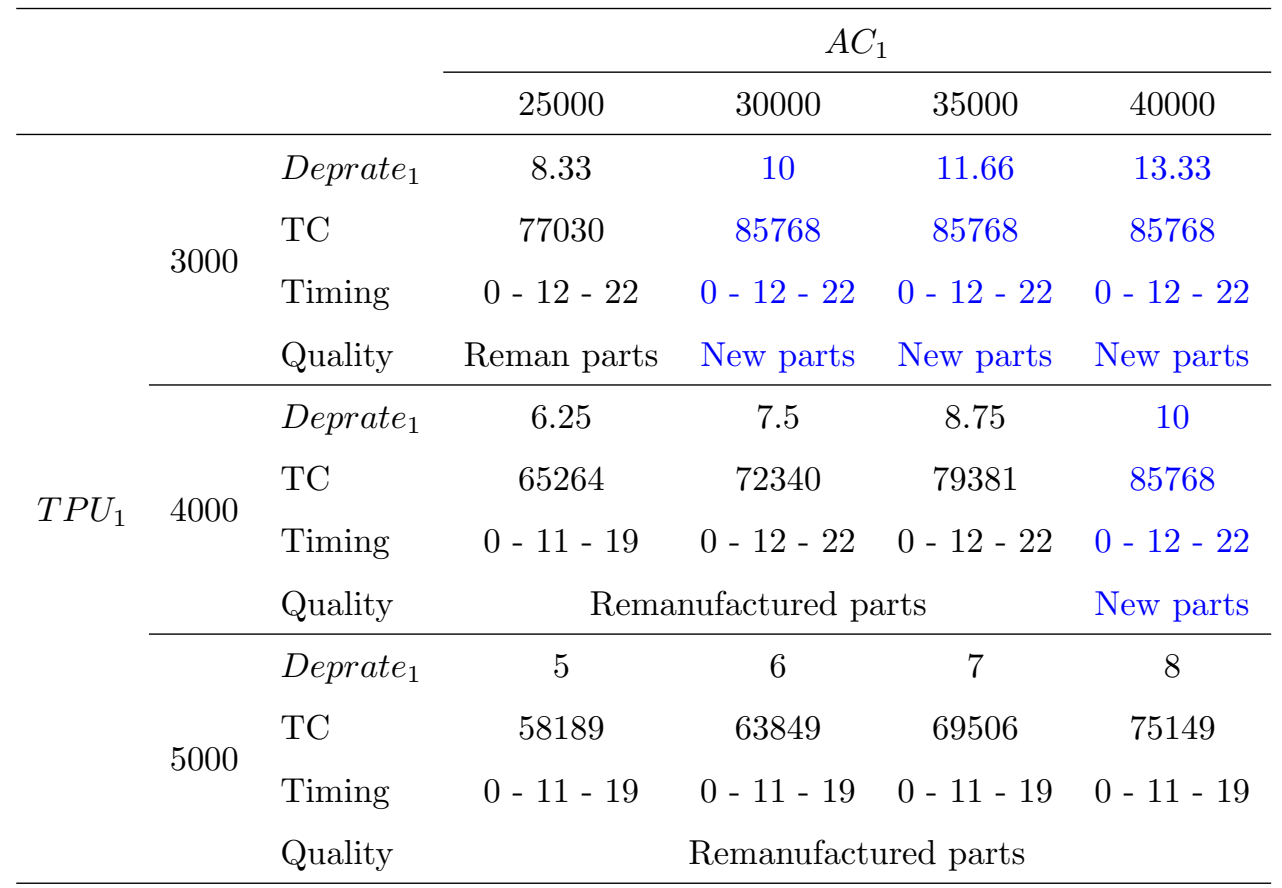

\subsection{Effect of the fixed remanufacturing cost on the remanufacturing plan} the returned part in the second case. This advantage allows reducing the labor hours and resource consumption when remanufacturing these parts at the OEM's facility; this helps cut the remanufacturing expenses. 


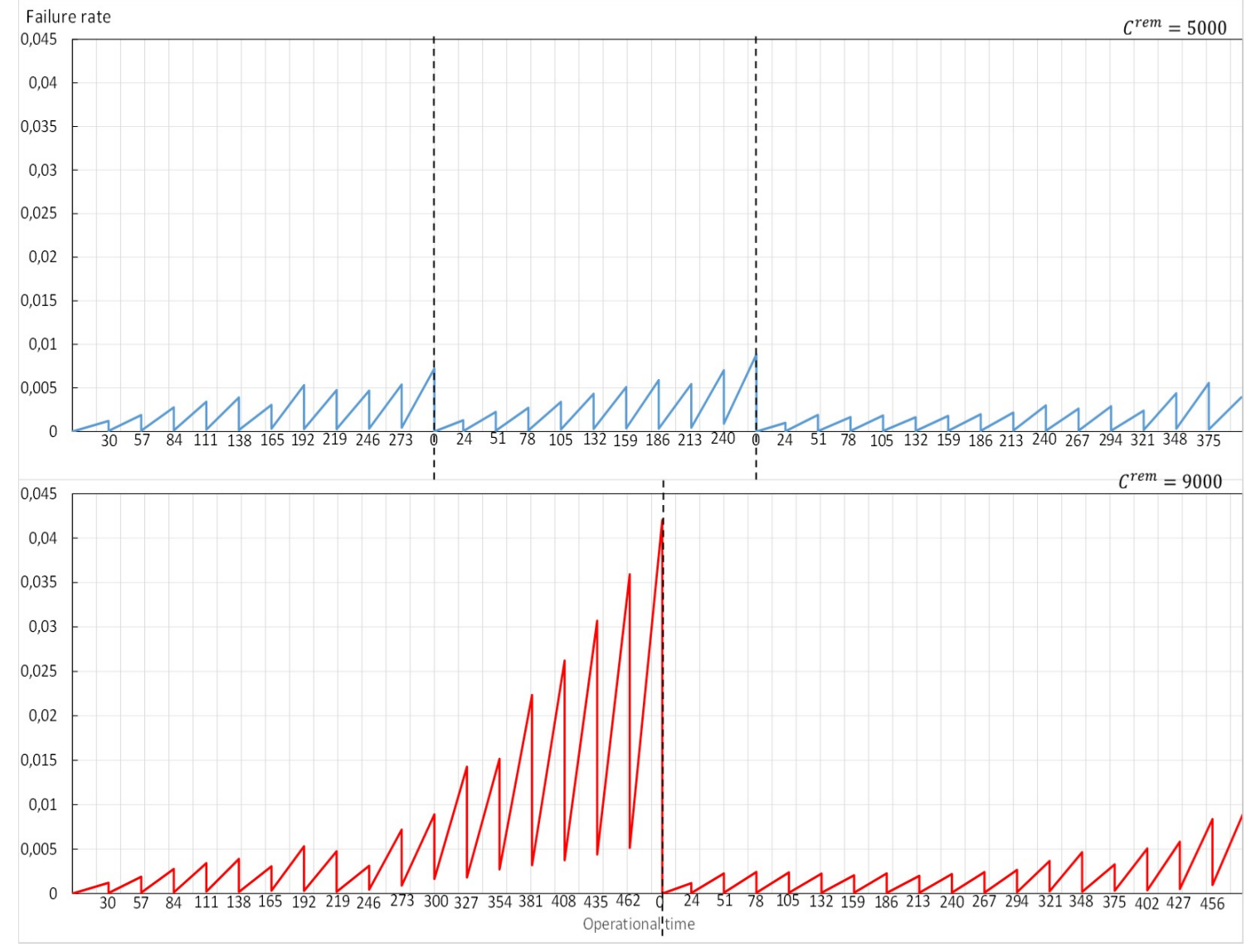

Fig. 14. The effect of $C^{r e m}$ on equipment's deterioration

With regard to the residual value of the equipment, one can clearly note that the recovered parts in the first case are more valuable than those in the second one. The two returned parts in the first case loose only about half of their original values, which is economically more advantageous for the user when replacing parts; whereas in the second case, the returned part loses almost four-fifths $(4 / 5)$ of its original value. By inference, performing the remanufacturing process early is preferable from both economic and technical perspectives, but when $C^{r e m}$ is very high, the remanufacturing is not recommended and it is better to defer it as long as possible.

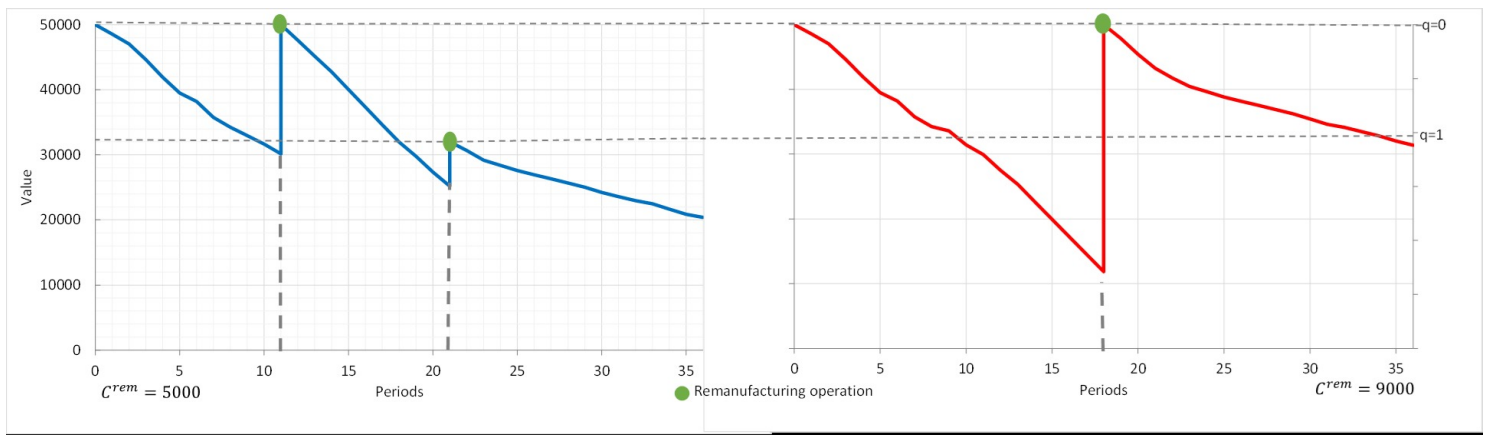

Fig. 15. The effect of $C^{r e m}$ on the equipment's value

\section{Conclusion}

The present paper aimed at investigating the interdependence between the operating conditions, remanufacturing decisions and life cycle costs in the machinery sector when new and remanufactured spare parts are used in the remanufacturing process. 
In order to analyze this interdependence, it was decided to consider a type of equipment intended to satisfy

deterministic and dynamic demands over a finite horizon that is divided into equal time periods. In order to reduce its failure rate, the equipment must undergo periodic and imperfect preventive maintenance actions. The equipment depreciation follows a modified activity-based model, in which both the intensity of use and the operating time are considered. In order to minimize the total life cycle costs during the production horizon, an integrated production and remanufacturing planning approach is proposed. A mixed integer non-linear program was developed in order to jointly optimize the production plan, timing and quality of the remanufacturing process. To solve the model, a genetic algorithm combined with fix and relax based rolling horizon heuristic were proposed.

Some illustrative examples were employed to show that the remanufacturing timing is more sensitive to the mode of use of the equipment and also to the fixed remanufacturing costs as compared to other parameters. As the production rate increases, it would be preferable to remanufacture the equipment early in order to avoid any excessive maintenance costs and high depreciation expenses. When the remanufacturing costs of the equipment are high, it is better to defer the remanufacturing process. Moreover, choosing the type of spare part to be used is directly related to the nature of the operating mode in subsequent periods. Indeed, it is preferable to perform the remanufacturing actions by using new spare parts for the main component when intensive production rates are scheduled. However, in the case of a moderate production mode, remanufactured parts with low depreciation rate (low cost and high production capacity) turn out to be more interesting as they give better economical advantage to the user as compared to new parts.

Furthermore, the integrated approach proposed here permits to generate higher profits, not only for the user but for the original equipment manufacturer (OEM) as well, especially in the case when a close and successful collaboration exist between these two partners. Applying this approach helps the OEMs to reduce third-parties remanufacturers (3PR) problems and also to partially solve the uncertainty problems by obtaining periodic approximated information about the value and the condition of the equipment in use.

Further research might be needed to focus on the environmental impacts of the production operations on the remanufacturing plans.

\section{Appendix}

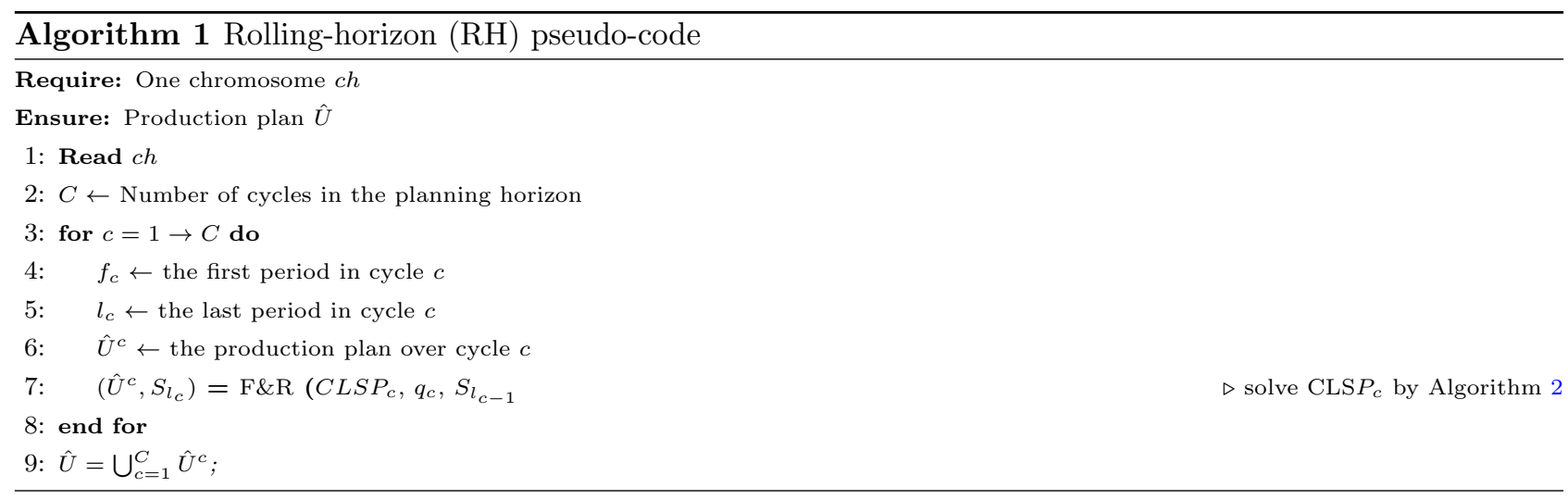




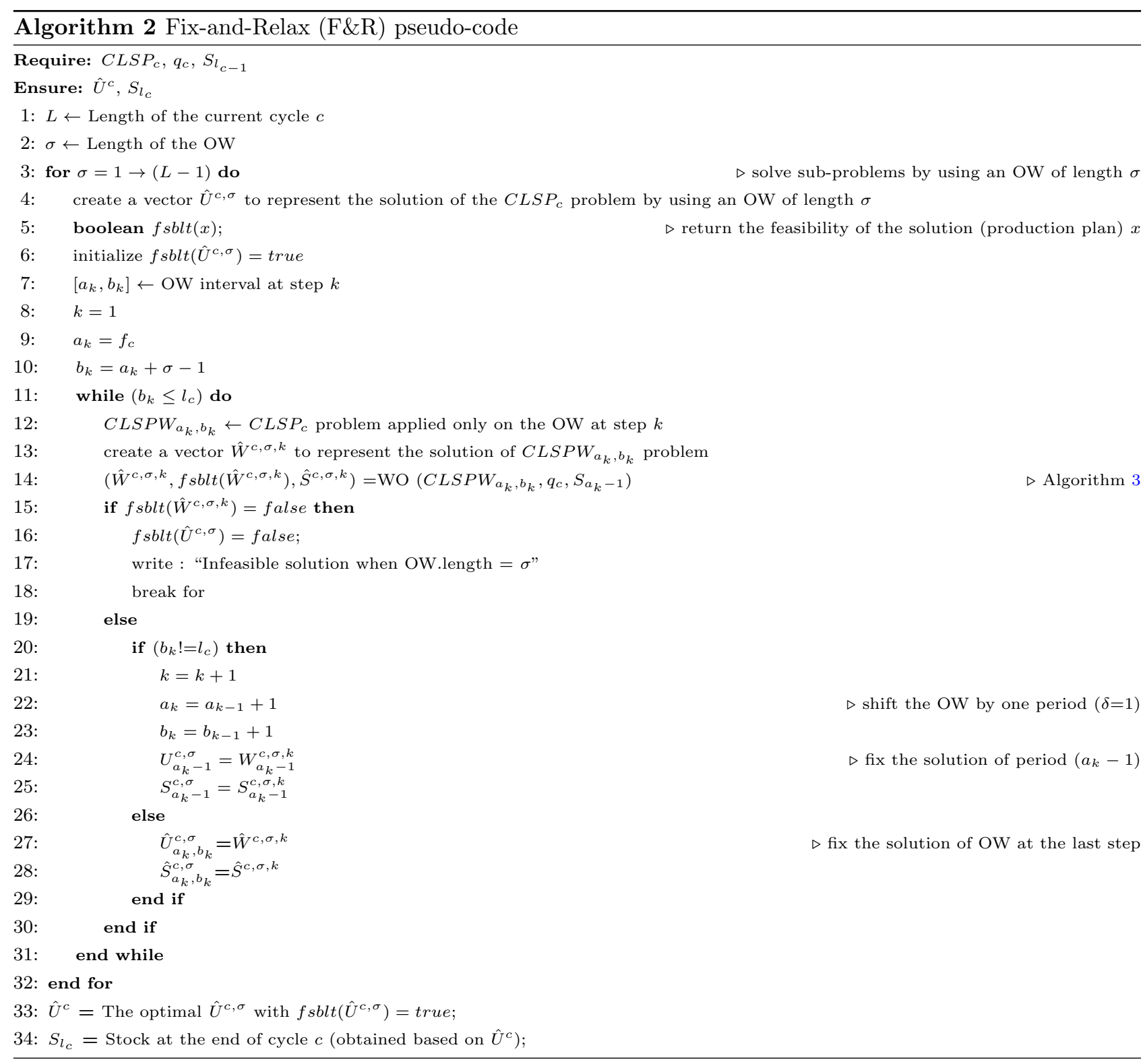




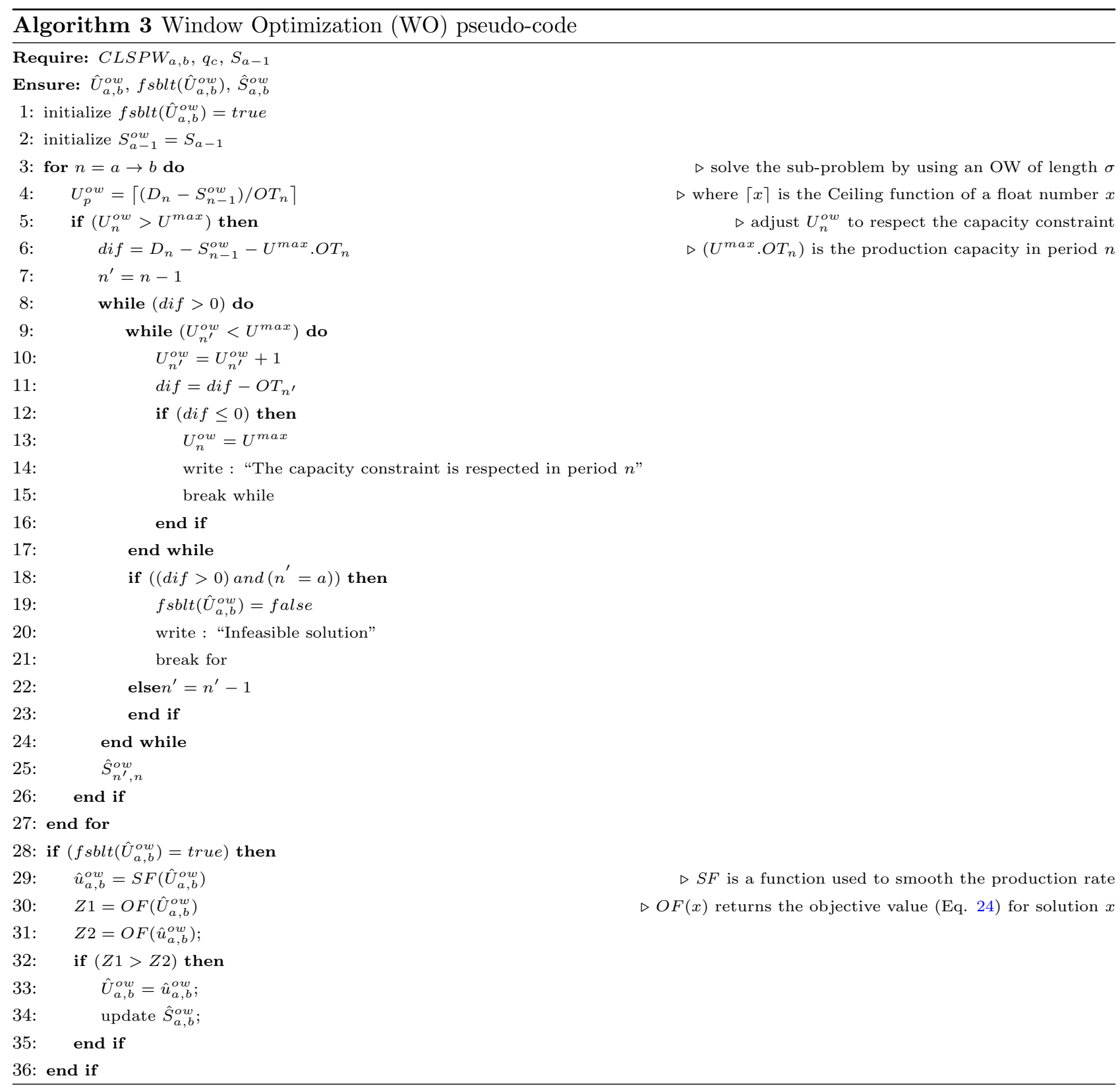

\section{References}

Abbey, J.D., Guide Jr, V.D.R., 2017. Closed-loop supply chains: a strategic overview, in: Sustainable Supply Chains. Springer, pp. 375-393. URL: https://doi.org/10.1007/978-3-319-29791-0_17, doi:10.1007/ 978-3-319-29791-0_17.

Agrawal, S., Singh, R.K., Murtaza, Q., 2015a. A literature review and perspectives in reverse logistics. Resources, Conservation and Recycling 97, 76-92. URL: https://doi.org/10.1016/j.resconrec.2015.02.009, doi:10.1016/j.resconrec. 2015.02.009.

Agrawal, V.V., Atasu, A., Van Ittersum, K., 2015b. Remanufacturing, third-party competition, and consumers' perceived value of new products. Management Science 61,60-72. URL: https://doi.org/10.1287/mnsc. 2014.2099, doi:10.1287/mnsc.2014.2099.

Atasu, A., Guide, V.D.R., Wassenhove, L.N., 2008. Product reuse economics in closed-loop supply chain 
research. Production and Operations Management 17, 483-496. URL: https://doi.org/10.3401/poms. 1080.0051, doi:10.1007/10.3401/poms.1080.0051.

Bengtsson, M., Kurdve, M., 2016. Machining equipment life cycle costing model with dynamic maintenance cost. Procedia CIRP 48, 102-107. URL: https://doi.org/10.1016/j.procir.2016.03.110, doi:10.1016/ j.procir.2016.03.110.

Beraldi, P., Ghiani, G., Grieco, A., Guerriero, E., 2008. Rolling-horizon and fix-and-relax heuristics for the parallel machine lot-sizing and scheduling problem with sequence-dependent set-up costs. Computers \& Operations Research 35,3644-3656. URL: https://doi.org/10.1016/j.cor.2007.04.003, doi:10.1016/ j.cor.2007.04.003.

Bhakthavatchalam, S., Diallo, C., Venkatadri, U., Khatab, A., 2015. Quality, reliability, maintenance issues in closed-loop supply chains: A review. IFAC-PapersOnLine 48, 460-465. URL: https://doi.org/10.1016/ j.ifacol.2015.06.124, doi:10.1016/j.ifacol.2015.06.124.

Boudhar, H., Dahane, M., Rezg, N., 2014. New dynamic heuristic for the optimization of opportunities to use new and remanufactured spare part in stochastic degradation context. Journal of Intelligent Manufacturing , 1-18URL: https://doi.org/10.1007/s10845-014-0989-1, doi:10.1007/s10845-014-0989-1.

Buschkühl, L., Sahling, F., Helber, S., Tempelmeier, H., 2010. Dynamic capacitated lot-sizing problems: a classification and review of solution approaches. Or Spectrum 32, 231-261. URL: https://doi.org/10. 1007/s00291-008-0150-7, doi:10.1007/s00291-008-0150-7.

Bushuev, M.A., Guiffrida, A., Jaber, M., Khan, M., 2015. A review of inventory lot sizing review papers. Management Research Review 38, 283-298. URL: https://doi.org/10.1108/MRR-09-2013-0204, doi:10. 1108/MRR-09-2013-0204.

Chari, N., Diallo, C., Venkatadri, U., 2014. State of the art on performability across the sustainable value chain. International Journal of Performability Engineering 10, 543-556.

Chari, N., Diallo, C., Venkatadri, U., Aït-Kadi, D., 2013. Manufacturing strategy using new and reconditioned rotable spare parts. 10.14279/depositonce-3753 URL: http://dx.doi.org/10.14279/depositonce-4720, doi:10.14279/depositonce-4720.

Chari, N., Diallo, C., Venkatadri, U., Khatab, A., 2016. Modeling and analysis of a warranty policy using new and reconditioned parts. Applied Stochastic Models in Business and Industry 32, 539-553. URL: https://doi.org/10.1002/asmb.2178, doi:10.1002/asmb. 2178.

Charter, M., Gray, C., 2007. Remanufacturing and product design: Designing for the 7th generation. Journal of manufacturing systems URL: https://research.uca.ac.uk/695/2/Remanufacturing_and_Product_ Design.pdf.

Cheng, G.Q., Zhou, B.H., Li, L., 2016. Joint optimisation of production rate and preventive maintenance in machining systems. International Journal of Production Research 54, 6378-6394. URL: https://doi.org/ 10.1080/00207543.2016.1174343, doi:10.1080/00207543.2016.1174343. 
Clark, A.R., 2005. Rolling horizon heuristics for production planning and set-up scheduling with backlogs and error-prone demand forecasts. Production Planning \& Control 16, 81-97. URL: https://doi.org/10.1080/ 09537280412331286565 , doi:10.1080/09537280412331286565.

Dillenberger, C., Escudero, L.F., Wollensak, A., Zhang, W., 1994. On practical resource allocation for production planning and scheduling with period overlapping setups. European Journal of Operational Research 75, 275286. URL: https://doi.org/10.1016/0377-2217(94)90074-4, doi:10.1016/0377-2217(94)90074-4. 
Du, Y., Cao, H., Liu, F., Li, C., Chen, X., 2012. An integrated method for evaluating the remanufacturability of used machine tool. Journal of Cleaner Production 20, 82-91. URL: https://doi.org/10.1016/j.jclepro. 2011.08.016, doi:10.1016/j.jclepro.2011.08.016.

Du, Y., Li, C., 2014. Implementing energy-saving and environmental-benign paradigm: machine tool remanufacturing by oems in china. Journal of Cleaner Production 66, 272-279. URL: https://doi.org/10.1016/ j.jclepro.2013.10.033, doi:10.1016/j.jclepro.2013.10.033.

Ferguson, M., Guide, V.D., Koca, E., Souza, G.C., 2009. The value of quality grading in remanufacturing. Production and Operations Management 18, 300-314. URL: https://doi.org/10.1111/j.1937-5956.2009. 01033.x, doi:10.1111/j.1937-5956.2009.01033.x.

Gao, W., Li, T., Peng, S.t., Wang, L., Zhang, H.c., 2016. Optimal timing and recycling operation mode for electro-mechanical products active remanufacturing. Frontiers of Engineering Management 3, $115-122$.

Geng, X., Gong, X., Chu, X., 2016. Component oriented remanufacturing decision-making for complex product using dea and interval 2-tuple linguistic topsis. International Journal of Computational Intelligence Systems 9, 984-1000. URL: https://doi.org/10.1080/18756891.2016.1237195, doi:10.1080/18756891. 2016.1237195 .

Glock, C.H., Grosse, E.H., Ries, J.M., 2014. The lot sizing problem: A tertiary study. International Journal of Production Economics 155, 39-51. URL: https://doi.org/10.1016/j.ijpe.2013.12.009, doi:10.1016/ j.ijpe.2013.12.009.

Goodall, P., Rosamond, E., Harding, J., 2014. A review of the state of the art in tools and techniques used to evaluate remanufacturing feasibility. Journal of Cleaner Production 81, 1-15. URL: https://doi.org/10. 1016/j.jclepro.2014.06.014, doi:10.1016/j.jclepro.2014.06.014.

Govindan, K., Soleimani, H., Kannan, D., 2015. Reverse logistics and closed-loop supply chain: A comprehensive review to explore the future. European Journal of Operational Research 240, 603-626. URL: https://doi . org/10.1016/j.ejor.2014.07.012, doi:10.1016/j.ejor.2014.07.012.

Grover, R., Grover, C., 2015. Obsolescence-a cause for concern? Journal of Property Investment \& Finance 33, 299-314. URL: https://doi.org/10.1108/JPIF-02-2015-0016, doi:10.1108/JPIF-02-2015-0016.

Hayashi, T., Katase, Y., Maejima, H., Yamaguchi, Y., Ueda, K., 2013. Recent renovations of dead-weight type force standard machines at nmij. Measurement 46, 4127-4134. URL: https://doi.org/10.1016/j. measurement.2013.07.027, doi:10.1016/j.measurement.2013.07.027.

Higham, A., Fortune, C., James, H., 2015. Life cycle costing: evaluating its use in uk practice. Structural Survey 33, 73-87. URL: https://doi.org/10.1108/SS-06-2014-0026, doi:10.1108/SS-06-2014-0026.

Ho, V.T., Hajej, Z., Le Thi, H.A., Rezg, N., 2015. Solving the production and maintenance optimization problem by a global approach, in: Modelling, Computation and Optimization in Information Systems and Management Sciences. Springer, pp. 307-318. URL: https://doi.org/10.1007/978-3-319-18167-7_27, doi:10.1007/978-3-319-18167-7_27. 
Hu, J., Jiang, Z., 2016. Optimal preventive maintenance for system in time-varying operation condition, in: Industrial Engineering and Engineering Management (IEEM), 2016 IEEE International Conference on, IEEE. pp. 496-500. URL: https://doi.org/10.1109/IEEM. 2016.7797925, doi:10.1109/IEEM.2016.7797925.

Ijomah, W.L., McMahon, C.A., Hammond, G.P., Newman, S.T., 2007. Development of design for remanufacturing guidelines to support sustainable manufacturing. Robotics and Computer-Integrated Manufacturing 23, 712-719. URL: https://doi.org/10.1016/j.rcim.2007.02.017, doi:10.1016/j.rcim.2007.02.017.

Jafari, L., Makis, V., 2015. Joint optimal lot sizing and preventive maintenance policy for a production facility subject to condition monitoring. International Journal of Production Economics 169, 156-168. URL: https: //doi.org/10.1016/j.rcim.2007.02.017, doi:10.1016/j.rcim.2007.02.017.

Jardine, A.K., Tsang, A.H., 2013. Maintenance, replacement, and reliability: theory and applications. CRC press.

Jayant, A., Gupta, P., Garg, S., 2012. Perspectives in reverse supply chain management (r-scm): A state of the art literature review. JJMIE 6.

Kafuku, J.M., Saman, M.Z.M., Sharif, S., Zakuan, N., et al., 2015. Investment decision issues from remanufacturing system perspective: literature review and further research. Procedia CIRP 26, 589-594. URL: https://doi.org/10.1016/j.procir.2014.07.043, doi:10.1016/j.procir.2014.07.043.

Karaulova, T., Bashkite, V., 2016. Decision-making framework for used industrial equipment. Engineering Economics 27, 23-31. URL: http://dx.doi.org/10.5755/j01.ee.27.1.8618, doi:10.5755/j01.ee.27.1. 8618.

Karimi, B., Ghomi, S.F., Wilson, J., 2003. The capacitated lot sizing problem: a review of models and algorithms. Omega 31, 365-378. URL: https://doi.org/10.1016/S0305-0483(03)00059-8, doi:10.1016/ S0305-0483(03) 00059-8.

Kumar, D., Westberg, U., 1997. Maintenance scheduling under age replacement policy using proportional hazards model and ttt-plotting. European journal of operational research 99, 507-515. URL: https://doi . org/10.1016/S0377-2217(96)00317-7, doi:10.1016/S0377-2217(96)00317-7.

Lambin, J.J., 2009. Capitalism and sustainable development. Symphonya. Emerging Issues in Management , 3-9URL: http://dx.doi.org/10.4468/2009.2.02lambin, doi:10.4468/2009.2.02lambin.

Lanza, G., Niggeschmidt, S., Werner, P., 2009. Optimization of preventive maintenance and spare part provision for machine tools based on variable operational conditions. CIRP Annals-Manufacturing Technology 58, 429432. URL: https://doi.org/10.1016/j.cirp.2009.03.030, doi:10.1016/j.cirp. 2009.03.030.

Lin, D., Zuo, M.J., Yam, R.C., 2000. General sequential imperfect preventive maintenance models. International Journal of reliability, Quality and safety Engineering 7, 253-266. URL: https://doi.org/10.1142/ S0218539300000213, doi:10.1142/S0218539300000213.

Liu, M., Ke, Q., Song, S., Zhou, X., 2013. Active remanufacturing timing determination based on failure state assessment, in: Reengineering Manufacturing for Sustainability. Springer, pp. 615-619. URL: https : //doi.org/10.1007/978-981-4451-48-2_100, doi:10.1007/978-981-4451-48-2_100. 
Lund, R.T., Mundial, B., 1984. Remanufacturing: the experience of the United States and implications for developing countries. volume 31. World Bank.

Malik, M.A.K., 1979. Reliable preventive maintenance scheduling. AIIE transactions 11, 221-228. URL:

Márquez, A.C., León, P., Fernández, J., Márquez, C.P., Campos, M.L., 2009. The maintenance management framework: A practical view to maintenance management. Journal of Quality in Maintenance Engineering 15, 167-178. URL: https://doi.org/10.1108/13552510910961110, doi:10.1108/13552510910961110.

Martinelli, F., 2005. Control of manufacturing systems with a two-value, production-dependent failure rate.

Nakagawa, T., 1988. Sequential imperfect preventive maintenance policies. IEEE Transactions on Reliability 37, 295-298. URL: https://doi.org/10.1109/24.3758, doi:10.1109/24.3758.

Olagunju, M., Yaru, S., 2014. Economic usability values of machine performance using computer algoritm. Computing, Information Systems, Development Informatics and Allied Research Journal 5, 13-16. 
Steingrímsson, J., Bilge, P., Heyer, S., Seliger, G., 2011. Business strategies for competition and collaboration for remanufacturing of production equipment, in: Advances in Sustainable Manufacturing. Springer, pp. 91-97. URL: https://doi .org/10.1007/978-3-642-20183-7_14, doi:10.1007/978-3-642-20183-7_14.

Palmer, R.J., Davis, H.H., 2004. Connecting concepts of business strategy and competitive advantage to activitybased machine cost allocations, in: Advances in Management Accounting. Emerald Group Publishing Limited, pp. $219-236$

Parker, S., 1997. Remanufacturing: The ultimate form of recycling. Technical Report. Air and Waste Management Association, Pittsburgh, PA (United States).

Priyono, A., Ijomah, W., Bititci, U., 2016. Disassembly for remanufacturing: A systematic literature review, new model development and future research needs. Journal of Industrial Engineering and Management 9, 899.

Qingdi, L., Dan, S.S.Z., 2013. Time interval decision-making methods for active remanufacturing product based on game theory and neural network. Journal of Mechanical Engineering 7, 006.

Saavedra, Y.M., Barquet, A.P., Rozenfeld, H., Forcellini, F.A., Ometto, A.R., 2013. Remanufacturing in brazil: case studies on the automotive sector. Journal of Cleaner Production 53, 267-276. URL: https: //doi.org/10.1016/j.jclepro.2013.03.038, doi:10.1016/j.jclepro.2013.03.038.

Schau, E.M., Traverso, M., Lehmann, A., Finkbeiner, M., 2011. Life cycle costing in sustainability assessment - a case study of remanufactured alternators. Sustainability 3, 2268-2288. URL: http://dx.doi.org/10. 3390/su3112268, doi:10.3390/su3112268.

Schraven, M., Heyer, S., Rütthard, N., 2012. Remanufacturing and reuse of production equipment at an automotive oem, in: Sustainable Manufacturing. Springer, pp. 125-130. URL: https://doi.org/10.1007/ 978-3-642-27290-5_19, doi:10.1007/978-3-642-27290-5_19.

Sharma, V., Garg, S., Sharma, P., 2015. Remanufacturing process: the case of heavy equipment support services. International Journal of Services and Operations Management 22, 40-59. URL: https://doi.org/ 10.1504/IJSOM. 2015.070882, doi:10.1504/IJSOM. 2015.070882.

Shi, W., Min, K.J., 2014. Product remanufacturing and replacement decisions under operations and maintenance cost uncertainties. The Engineering Economist 59, 154-174. URL: https://doi.org/10.1080/0013791X. 2014.884662, doi:10.1080/0013791X.2014.884662.

da Silva, E.J., Ometto, A.R., Rozenfeld, H., Silva, D.A.L., Pigosso, D.C.A., Reis, V.R.A., 2012. Prototypical implementation of a remanufacturing oriented grinding machine, in: Leveraging Technology for a Sustainable World. Springer, pp. 257-262. URL: https://doi.org/10.1007/978-3-642-29069-5_44, doi:10.1007/978-3-642-29069-5_44.

Sinha, P., Muthu, S.S., Dissanayake, G., 2016. The remanufacturing industry and fashion, in: Remanufactured Fashion. Springer, pp. 1-9. URL: https://doi.org/10.1007/978-981-10-0297-7_1, doi:10.1007/ 978-981-10-0297-7_1. 
Wang, D., Tang, O., Zhang, L., 2014. A periodic review lot sizing problem with random yields, disruptions and inventory capacity. International Journal of Production Economics 155, 330-339. URL: https://doi.org/ 10.1016/j.ijpe.2014.02.007, doi:10.1016/j.ijpe.2014.02.007.

Wei, S., Tang, O., Sundin, E., 2015. Core (product) acquisition management for remanufacturing: a re1186/s13243-015-0014-7.

Yan, C., 2013. Remanufacturing and benefits analysis of construction machinery hydraulic valves, in: Applied Mechanics and Materials, Trans Tech Publ. pp. 2266-2270.

Yang, Q., 2014. Remanufacturing versus new acquisition of production equipment: Definitions and decisionmaking checklist. URL: http://www.diva-portal.org/smash/record.jsf?pid=diva2\%3A775806\&dswid= $-7371$.

Yaoling, H., 2012. International comparison and the enlightenment on machine tool remanufacturing industry development [j]. Recyclable Resources and Circular Economy 2, 015. URL: http://en.cnki.com.cn/ Article_en/CJFDTOTAL-ZSZY201202015.htm. end of life construction machinery remanufacturing. Journal of Cleaner Production 124, 191-203. URL: https://doi.org/10.1016/j.jclepro.2016.02.070, doi:10.1016/j.jclepro.2016.02.070.

Yiqing, Z., Zhiyong, Z., Yun, X., Wen, W., 2006. Research and application of automation technology in renovation for old import machine tool, in: IET Conference Publications, pp. 2134-2137. URL: http: //dx.doi.org/10.1049/cp:20061125, doi:10.1049/cp:20061125. 
You, M.Y., Li, H., Meng, G., 2011. Control-limit preventive maintenance policies for components subject to imperfect preventive maintenance and variable operational conditions. Reliability Engineering \& System Safety 96, 590-598. URL: https://doi.org/10.1016/j.ress.2010.12.015, doi:10.1016/j.ress.2010. 12.015 .

Zhang, T., Chu, J., Wang, X., Liu, X., Cui, P., 2011. Development pattern and enhancing system of automotive components remanufacturing industry in china. Resources, Conservation and Recycling 55, 613-622. URL: https://doi.org/10.1016/j.resconrec.2010.09.015, doi:10.1016/j.resconrec.2010.09.015.

Zhao, X., Fouladirad, M., Bérenguer, C., Bordes, L., 2010. Condition-based inspection/replacement policies for non-monotone deteriorating systems with environmental covariates. Reliability Engineering \& System Safety 95, 921-934. URL: https://doi.org/10.1016/j.ress.2010.04.005, doi:10.1016/j.ress.2010.04.005.

Zhou, J., Huang, P., Zhu, Y., Deng, J., 2012. A quality evaluation model of reuse parts and its management system development for end-of-life wheel loaders. Journal of Cleaner Production 35, 239-249. URL: https: //doi.org/10.1016/j.jclepro.2012.05.037, doi:10.1016/j·jclepro.2012.05.037. 